\title{
An enhanced broadband class-J mode power amplifier for 5G
}

\section{smart meter applications [version 1; peer review: awaiting}

\section{peer review]}

\author{
Nagisetty Sridhar (D), Dr Chinnaiyan Senthilpari (D), Dr Mardeni R (D), \\ Dr Wong Hin Yong
}

FACULTY OF ENGINEERING, MULTIMEDIA UNIVERSITY, CYBERJAYA, SELANGOR, 63100, Malaysia

\author{
V1 First published: 29 Oct 2021, 10:1099 \\ https://doi.org/10.12688/f1000research.73498.1 \\ Latest published: 29 Oct 2021, 10:1099 \\ https://doi.org/10.12688/f1000research.73498.1
}

\section{Abstract}

Background: With the tremendous increase in the usage of smart meters for industrial/ household purposes, their implementation is considered a crucial challenge in the Internet of Things (IoT) world, leading to a demand for emerging $5 G$ technology. In addition, a large amount of data has to be communicated by smart meters efficiently, which needs a significant enhancement in bandwidth. The power amplifier (PA) plays a major role in deciding the efficiency and bandwidth of the entire communication system. Among the various modes of PAs, a newly developed Class-J mode PA has been proven to achieve high efficiency over a wide bandwidth by maintaining linearity.

Methods: This paper proposes a Class-J mode PA design methodology using a CGH40010F-GaN device that operates at a $3.5 \mathrm{GHz}$ frequency to meet the requirements of $5 \mathrm{G}$ wireless communication technology for the replacement of existing 4G/LTE technology used for advanced metering infrastructure (AMI) in smart grids. This research's main objective is to design the proper matching networks (M.Ns) to achieve Class-J mode operation that satisfies the bandwidth requirements of $5 \mathrm{G}$ smart grid applications. With the target impedances obtained using the load-pull simulation, lumped element matching networks are analyzed and designed in 3 ways using the ADS EDA tool.

Results: The simulation results reveal that the proposed Class-J PA provides a maximum drain efficiency (D.E) of $82 \%$, power added efficiency (PAE) of $67 \%$ with $13 \mathrm{~dB}$ small-signal gain at $3.5 \mathrm{GHz}$, and output power of $40 \mathrm{dBm}$ (41.4 dBm peak) with a power gain of approximately $7 \mathrm{~dB}$ over a bandwidth of approximately $400 \mathrm{MHz}$ with a $28 \mathrm{~V}$ power supply into a $50 \Omega$ load.

Conclusion: The efficiency and bandwidth of the proposed Class-J PA can be enhanced further by fine-tuning the matching network design to make it more suitable for $5 \mathrm{G}$ smart meter/grid applications.

\section{Open Peer Review}

Approval Status AWAITING PEER REVIEW

Any reports and responses or comments on the article can be found at the end of the article. 
Keywords

5G, 3.5 GHz, power amplifier, good efficiency, wide bandwidth, Class-J, matching networks

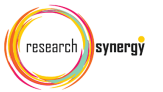

vinis

This article is included in the Research Synergy

Foundation gateway.

Corresponding author: Nagisetty Sridhar (sridharnagisetty@gmail.com)

Author roles: Sridhar N: Conceptualization, Data Curation, Formal Analysis, Investigation, Methodology, Resources, Software, Visualization, Writing - Original Draft Preparation; Senthilpari DC: Funding Acquisition, Project Administration, Resources, Supervision, Validation, Writing - Review \& Editing; R DM: Funding Acquisition, Resources, Supervision, Validation, Writing - Review \& Editing; Hin Yong DW: Funding Acquisition, Project Administration, Validation, Writing - Review \& Editing

Competing interests: No competing interests were disclosed.

Grant information: This research work was funded by the Ministry of Higher Education (MOHE), Malaysia, under FRGS grants (FRGS/1/2019/TK04/MMU/02/19).

The funders had no role in study design, data collection and analysis, decision to publish, or preparation of the manuscript.

Copyright: ( $) 2021$ Sridhar $\mathrm{N}$ et al. This is an open access article distributed under the terms of the Creative Commons Attribution License, which permits unrestricted use, distribution, and reproduction in any medium, provided the original work is properly cited.

How to cite this article: Sridhar N, Senthilpari DC, R DM and Hin Yong DW. An enhanced broadband class-J mode power amplifier for 5G smart meter applications [version 1; peer review: awaiting peer review] F1000Research 2021, 10:1099

https://doi.org/10.12688/f1000research.73498.1

First published: 29 Oct 2021, 10:1099 https://doi.org/10.12688/f1000research.73498.1 


\section{Introduction}

With the tremendous improvement in the wireless communication industry, the demand for emerging $5 \mathrm{G}$ technology ${ }^{1-3}$ has increased for enhanced broadband and Internet of Things (IoT) applications. Today, many smart devices introduce intelligent behavior into households and industrial equipment to realize smart grids and smart homes/cities. For example, a smart energy meter can measure energy consumption by one device and send the data to the energy provider along with the end consumer statistics using two-way wireless communication technology. Although the existing $4 \mathrm{G}$ technology has served us well to date, it cannot satisfy the new challenges that can be brought by emerging wireless communication applications such as $5 \mathrm{G}$ smart grids, as a large amount of data transfer is needed at higher data rates with low latency. Hence, the adoption of $5 \mathrm{G}$ technology becomes more crucial. Therefore, worldwide research has started to implement this $5 \mathrm{G}$ technology by adopting techniques such as millimeter waves, small cells, massive MIMO, beamforming, and full duplexing. ${ }^{4}$ However, the two major challenges to be solved while implementing this $5 \mathrm{G}$ technology for these applications are a reduction in energy consumption ${ }^{5}$ and an enhancement in bandwidth. As the PAE of the power amplifiers ${ }^{6,7}$ used in the R.F. transmitter plays the key role in deciding the energy consumption by the overall $5 \mathrm{G}$ wireless communication network, a power amplifier is needed that can provide improvement in PAE without compromising linearity and bandwidth. Many PA topologies have been reported previously ${ }^{8-14}$ with various techniques to achieve linear amplification with high efficiency. Switching mode PAs such as Class-E/F demonstrate potential in providing excellent PAE but are not beneficial for enhanced bandwidth $5 \mathrm{G}$ applications because of their narrow bandwidth nature of harmonic terminations. On the other hand, linear mode PAs such as Class-A/B can achieve lower efficiency but are more linear than switching mode PAs. Nevertheless, Class-B mode PAs with harmonic tuning can theoretically achieve a peak efficiency of approximately $78.5 \%$, and their bandwidth is also limited, as harmonic termination is difficult to realize over a wide bandwidth. However, this study mainly focuses on the design of a power amplifier that satisfies the requirements of smart grid wireless communication networks that ${ }^{15,16}$ used for AMI of smart meters. A distributed communication architecture that can provide cost-effective and efficient communication is proposed in. ${ }^{17}$ Distributed operation centers presently use $3 \mathrm{G} / 4 \mathrm{G}$ cellular networks to communicate with data concentrators, which can be replaced by emerging $5 \mathrm{G}$ communication technology to support the increase in data traffic. A comprehensive review of $5 \mathrm{G}$ wireless communication networks for smart grids is presented in, ${ }^{18}$ which motivates PA designers to design a PA that overcomes the bandwidth limitations of existing linear and switching mode PAs and satisfies the bandwidth requirements of $5 \mathrm{G}$ wireless communications in smart grids. A newly developed Class-J mode PA by S.C. Cripps in ${ }^{19}$ has proven its potential in achieving high efficiency without compromising linearity and bandwidth. The design methodology for highly efficient, linear, and broadband Class-J PA mode is demonstrated in. ${ }^{20}$ Different Class-J mode PAs were reviewed to analyze their suitability for near-future $5 \mathrm{G}$ wireless communications used for smart grid applications. Of these PAs, the design of a 0.5 W GaN-based integrated Class-J PA that considers output matching network element losses for realizing on-chip output matching is presented in, ${ }^{21}$ but because of the limitations of device technology and the low-Q on-chip matching network losses, its efficiency and output power are less than those of discrete PAs. An integrated Class-J PA using CMOS technology is presented in, ${ }^{22}$ where the effect of knee voltage is considered to analyze 2 nd harmonic losses for deriving modified design equations. However, the staked FET must be used for implementation because of the CMOS PA's low breakdown voltage. The improvement in power output and D. E of a Class-J PA was presented in ${ }^{23,24}$ by realizing a proper half-wave rectified sinusoidal waveform at the gate of the transistor. Apart from the usefulness of this method, it needs additional circuitry because of higher-order filters, which complicates the design and implementation of the PA. A methodology to improve the Class-J PA's performance by injecting the active power at the $2^{\text {nd }}$ harmonic frequency has been proposed in, ${ }^{25}$ which causes an improvement in drain efficiency, but because of doubling and filtering, the design becomes complicated, and an increase in chip area makes it less appealing for integration. Based on the literature, it is understood that among the various modes of PAs, a Class-J PA can even satisfy the enhanced bandwidth requirement of the emerging 5G smart meter/smart grid applications without sacrificing linearity and efficiency if the appropriate matching networks are designed. Therefore, in this paper, a Class-J mode PA is chosen, and a design methodology is proposed to achieve the efficiency and bandwidth requirements of $5 \mathrm{G}$ wireless communications of smart grids. However, the important point to be considered when designing a PA for these smart grid applications is the frequency at which it has to be operated. Hence, different frequency bands, including LTE and 5G NR (new radio), ${ }^{26-28}$ are analyzed to choose the appropriate operating frequency of the proposed Class-J PA. Recently, a frequency band termed citizen broadband radio service (CBRS) with $3.5 \mathrm{GHz}$ center frequency (i.e., $5 \mathrm{G}$ sub6 GHz frequency) was allocated for public usage. ${ }^{29}$ This spectrum provides good space for $5 \mathrm{G}$ smart grid wireless communication applications. Hence, Initially, the proposed Class-J mode PA was designed to operate at a center frequency of $3.5 \mathrm{GHz}$ (sub $<6 \mathrm{GHz}$ ) $5 \mathrm{G}$ frequency). The main contribution of this research paper involves analysis of various matching network methods/topologies and design of appropriate $\mathrm{I} / \mathrm{P}$ and $\mathrm{O} / \mathrm{P}$ matching networks to match a $50 \Omega$ source and loads with the desired optimum source and load impedances of the transistor with respect to maximum PAE determined by load pull to achieve Class-J mode operation with the desired bandwidth of $5 \mathrm{G}$ smart grid specifications. The PA simulations were performed in the Advanced Design Systems (ADS) EDA tool, and this paper's structure is described as follows. A stepwise design procedure of a Class-J PA based on its theory with three approaches of lumped element-based input and output M. Ns for matching a $50 \Omega$ source and load terminations with the transistor's optimum source and load impedances to obtain Class-J mode operation is 
described in the Methodology section. The schematic Class-J PA circuit simulation results as per the design methodology and their comparison with similar recent works are presented in the Results and Discussion sections. Finally, the advantages and limitations of this proposed research work are detailed in the Conclusions.

\section{Methods}

From the theory of the Class-J operation mode introduced and developed by S.C. Cripps, ${ }^{19}$ the high-efficiency amplification in broadband can be obtained by terminating the output of transistor $M_{1}$ to appropriate fundamental $\left(\mathrm{Z}_{\mathrm{f0}}\right)$ and second harmonic $\left(\mathrm{Z}_{2 \mathrm{f0}}\right)$ optimal load impedances, as shown in Equations (1) and (2), at different frequencies over the desired bandwidth, as shown in Figure 2(a).

$$
\begin{gathered}
\mathrm{Z}_{\mathrm{f} 0}=\frac{\left(\mathrm{V}_{\mathrm{DD}}-\mathrm{V}_{\mathrm{th}}\right)(1+\mathrm{j} \alpha)}{\operatorname{Imax} / 2}=\mathrm{R}_{\mathrm{opt}}+\mathrm{j} \alpha \mathrm{R}_{\mathrm{opt}} \\
\mathrm{Z}_{2 \mathrm{f} 0}=-\frac{\left(\mathrm{V}_{\mathrm{DD}}-\mathrm{V}_{\mathrm{th}}\right) \mathrm{j} \alpha}{2\left(\frac{\mathrm{I}_{\max }}{3 \pi}\right)}=-\frac{\mathrm{j} 3 \pi}{8} \alpha \mathrm{R}_{\mathrm{opt}}
\end{gathered}
$$

where $R_{\text {opt }}$ is the optimum resistance, which can be expressed as shown in Equation (3).

$$
\mathrm{R}_{\mathrm{opt}}=2\left(\mathrm{~V}_{\mathrm{DD}}-\mathrm{V}_{\mathrm{th}}\right) / \mathrm{I}_{\max }
$$

With these optimum load impedances presented, from Figure 1, we can observe that the drain voltage $\left(\mathrm{V}_{\mathrm{DS}}\right)$ is boosted with a phase shift.

Thus, the phase shift and boost in drain voltage $\left(\mathrm{V}_{\mathrm{DS}}\right)$ cause a slight overlap with drain current $\left(\mathrm{I}_{\mathrm{D}}\right)$, making the Class- $\mathrm{J}$ power amplifier highly efficient. Although this waveform shows the feature of a switching mode PA, the Class-J mode PA can provide linearity similar to the Class-B or AB modes because of its non-switching mode of operation. Unlike in Class-B, harmonic traps are unnecessary, making it suitable for wideband $5 \mathrm{G}$ applications.

The various steps involved in the design methodology of the proposed Class-J PA are discussed, as illustrated in the flowchart shown in Figure 2(b).

\section{Selection of the transistor and technology}

As per the trend of designing a power amplifier, the Advanced Design System (ADS) tool was used to design, and a CREE Device model (CGH40010F) based on GaN technology was used for simulation. The CGH40010F GaN transistor is chosen based on the features mentioned in its datasheet to obtain the desired power output required for smart meter applications. The gate threshold voltage $\left(\mathrm{V}_{\text {th }}\right)$ and gate quiescent voltage $\left(\mathrm{VG}_{\mathrm{Q}}\right)$ of the chosen $(\mathrm{CGH} 40010 \mathrm{~F}) \mathrm{GaN}$

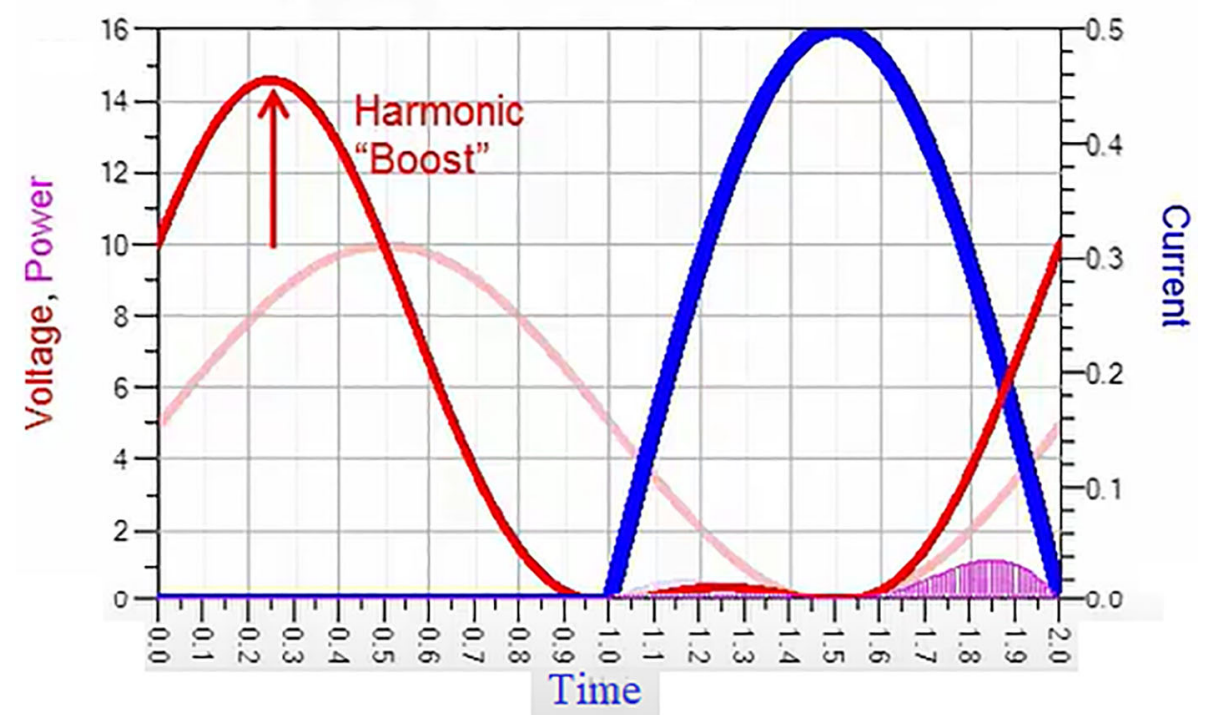

Figure 1. Class-J mode voltage and current waveforms. 
transistor can also be obtained from its datasheet. To obtain a Class-J PA mode, the load impedances to be presented to this transistor (M1) (i.e., (CGH40010F) GaN transistor) are calculated theoretically using Equations (1) and (2) and can be verified using the Class-J workspace in the ADS design tool.

Selection of the biasing Network

As per the design idea of the power amplifier for this work, the supply voltage $\mathrm{V}_{\mathrm{DD}}=28 \mathrm{~V}$ and gate bias voltage $\mathrm{V}_{\mathrm{GG}} \cong$ $\mathrm{V}_{\mathrm{K}}$ (threshold voltage) (i.e., with a quiescent bias current of $\mathrm{I}_{\mathrm{q}}=2 \%$ of Imax) are chosen based on the (CGH40010F) GaN transistor's $\left(\mathrm{M}_{1}\right)$ datasheet for biasing it through a fixed-bias network to operate as a Class-B PA to obtain a half-wave rectified drain current $\left(I_{D}\right)$. With the use of the fixed-bias network shown in Figure 3(a), the DC-IV characteristics of the

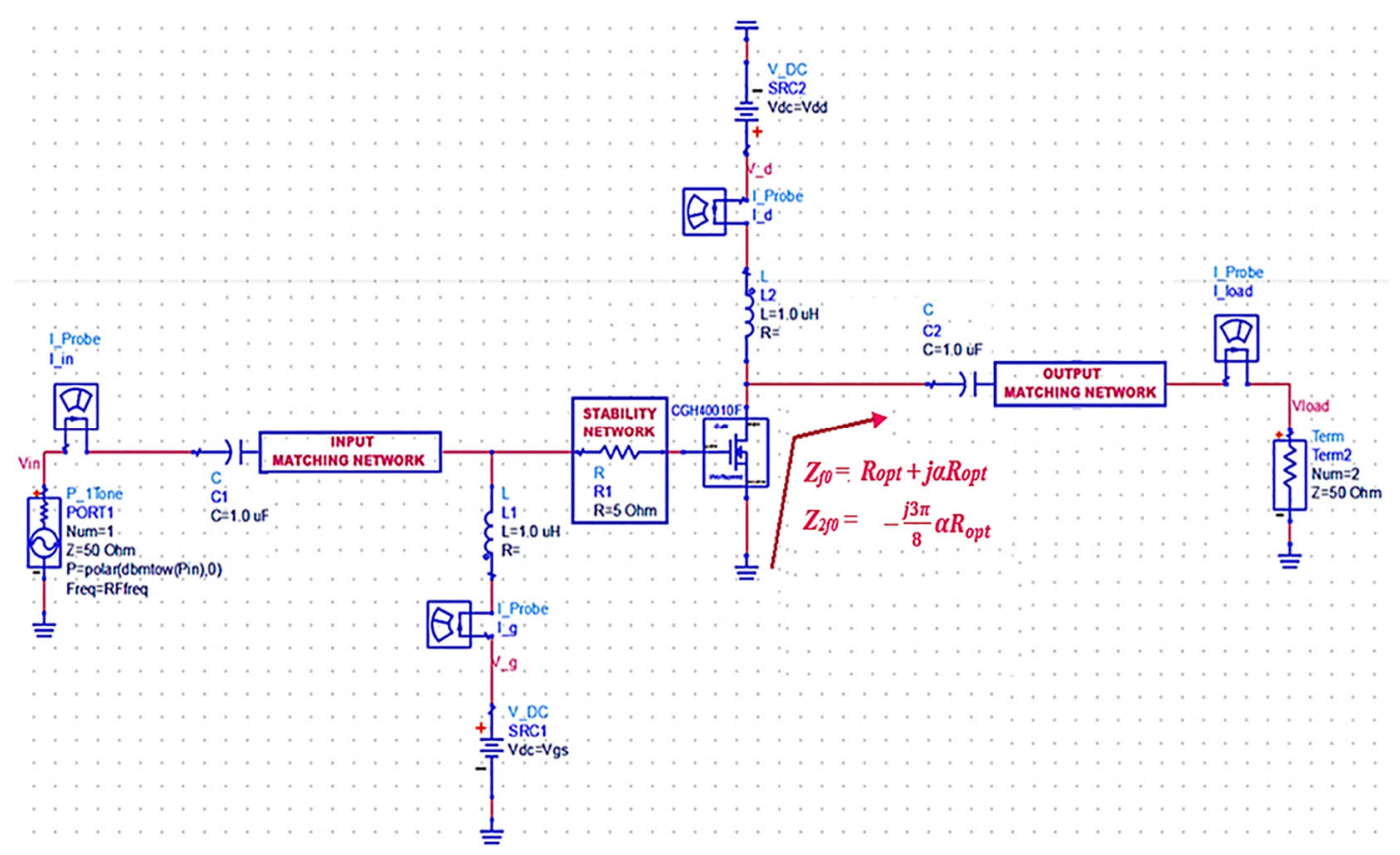

Figure 2(a). Sample Class-J mode PA topology.

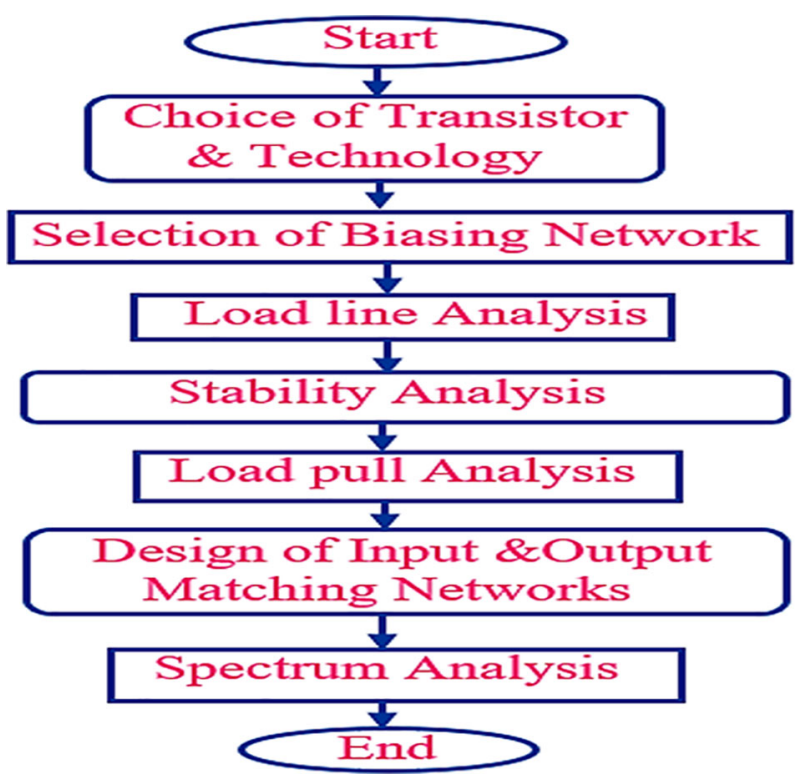

Figure 2(b). Flow chart. 


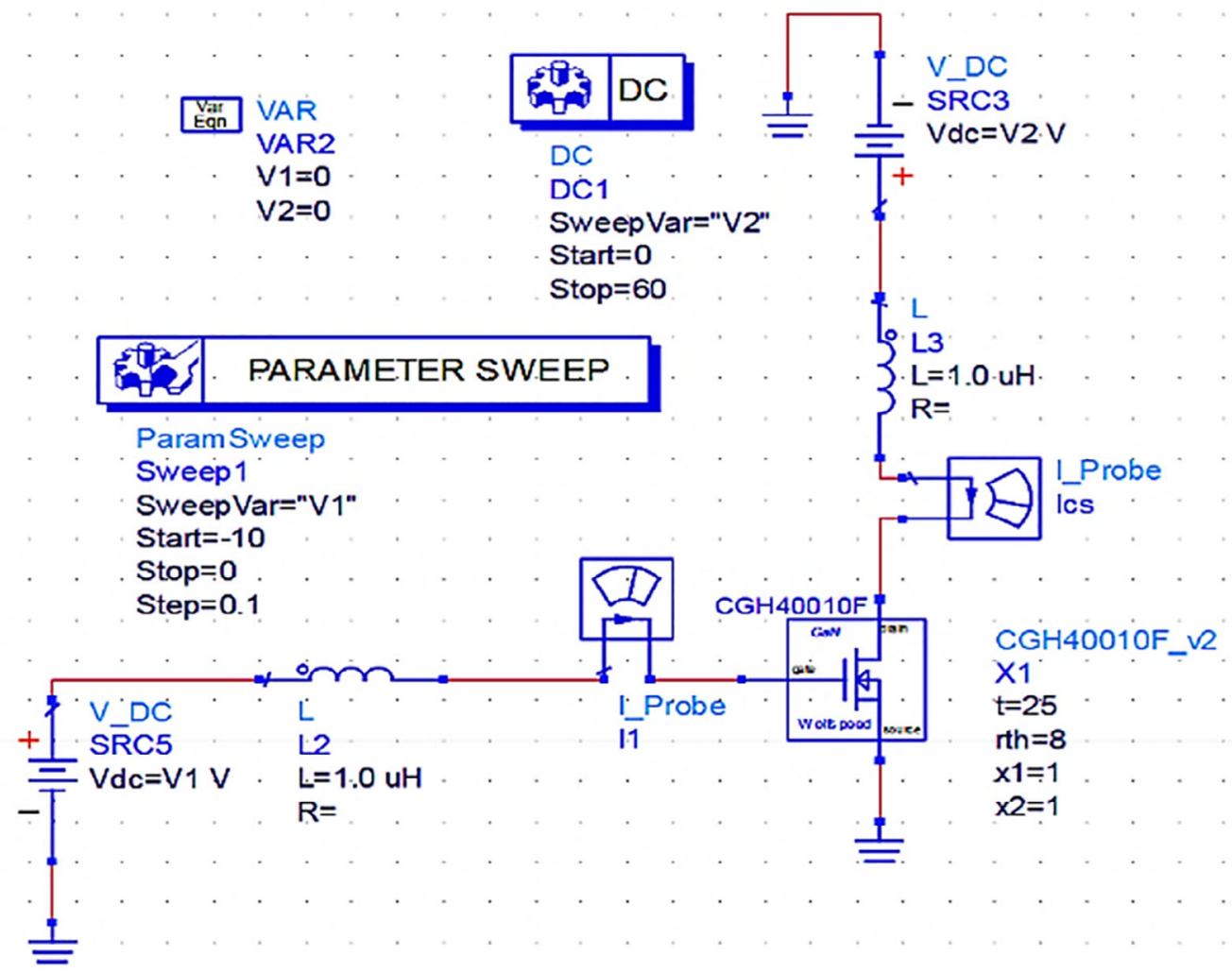

Figure 3(a). Fixed-bias network of GaN transistor.

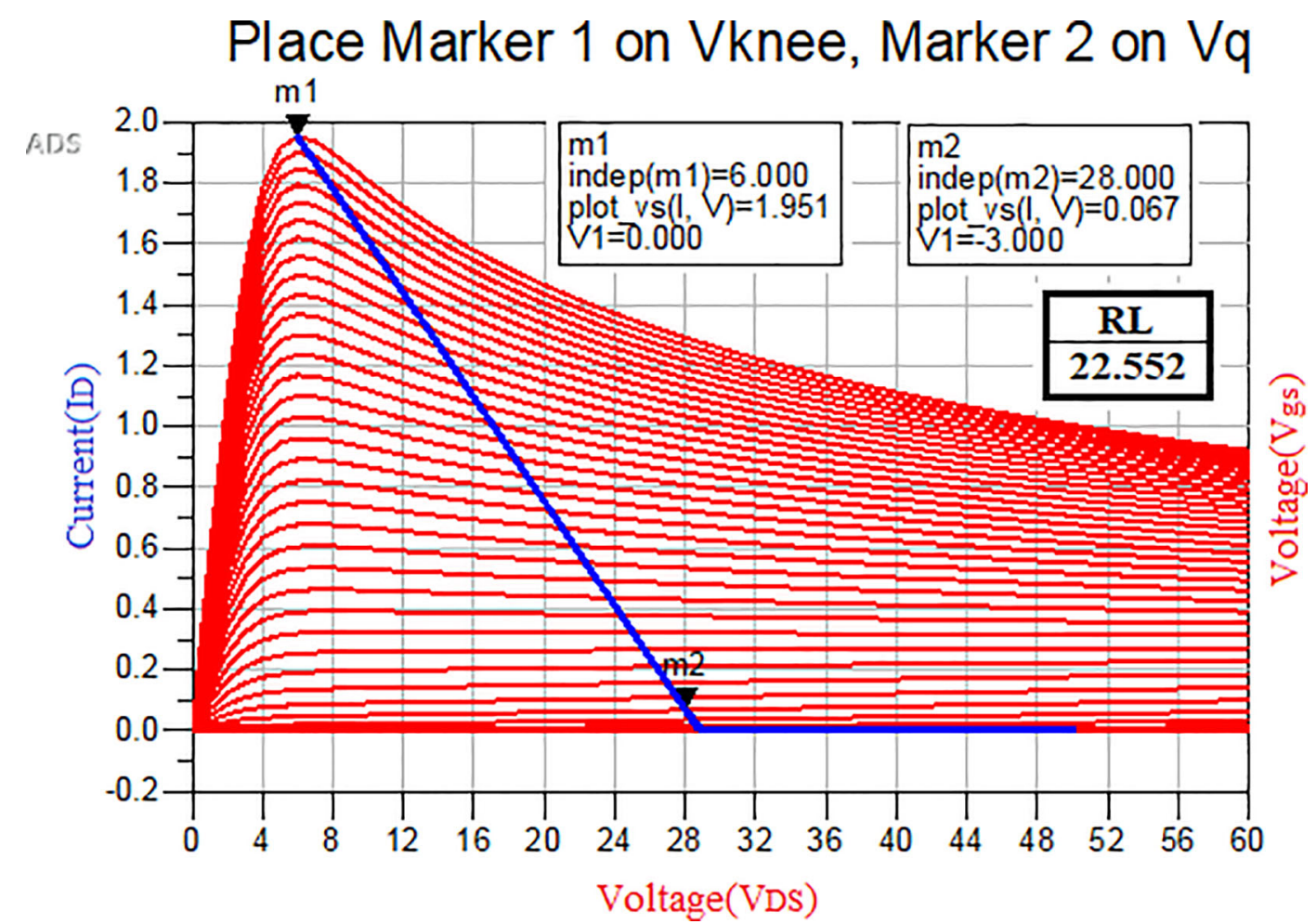

Figure 3(b). DC-IV Characteristics of GaN transistor. 
CGH40010F GaN transistor are drawn, and the quotient (Q) or bias point is obtained by adjusting marker $\mathrm{m} 2$ on the load line to operate it in Class-B mode, as shown in Figure 3(b).

Stability analysis

After choosing the bias point of the transistor while designing the power amplifier, one of the most important considerations is that it should be unconditionally stable irrespective of the frequency under normal operating conditions. To maintain the PA's stability at low frequencies, a stabilization circuit with a resistor connected in series with the transistor gate terminal is employed based on the datasheet of the $\mathrm{CGH} 40010 \mathrm{~F} \mathrm{GaN}$ transistor. This series resistance can stabilize the transistor across the entire range of desired frequencies. To ensure the unconditional stability of the PA, the main conditions to be satisfied are that the Rollet stability factor is more than unity (i.e., $(K>1)$ ) and the stability measure (b) is positive. The Rollet stability and stability measures can be calculated theoretically by Equations (4) and (5), respectively.

$$
\begin{gathered}
K=\left\{1-\left|S_{11}\right|^{2}-\left|S_{22}\right|^{2}+\left|S_{11 *} S_{22}-S_{12 *} S_{21}\right|^{2}\right\} /\left\{2 *\left|S_{12 *} S_{21}\right|\right\} \\
b=\left\{1+\left|S_{11}\right|^{2}-\left|S_{22}\right|^{2}-\left|S_{11 *} S_{22}-S_{12 *} S_{21}\right|^{2}\right\}
\end{gathered}
$$

However, practically unconditional stability of the PA can be ensured using Network Analyzer for S-Parameters (SP_NWA) from simulation instrument components, and the stability factor and its variation w.r.t. frequency can be obtained with the use of measurement expression functions and data display templates in Advanced Design System (ADS) tool, as shown in Figure 4.

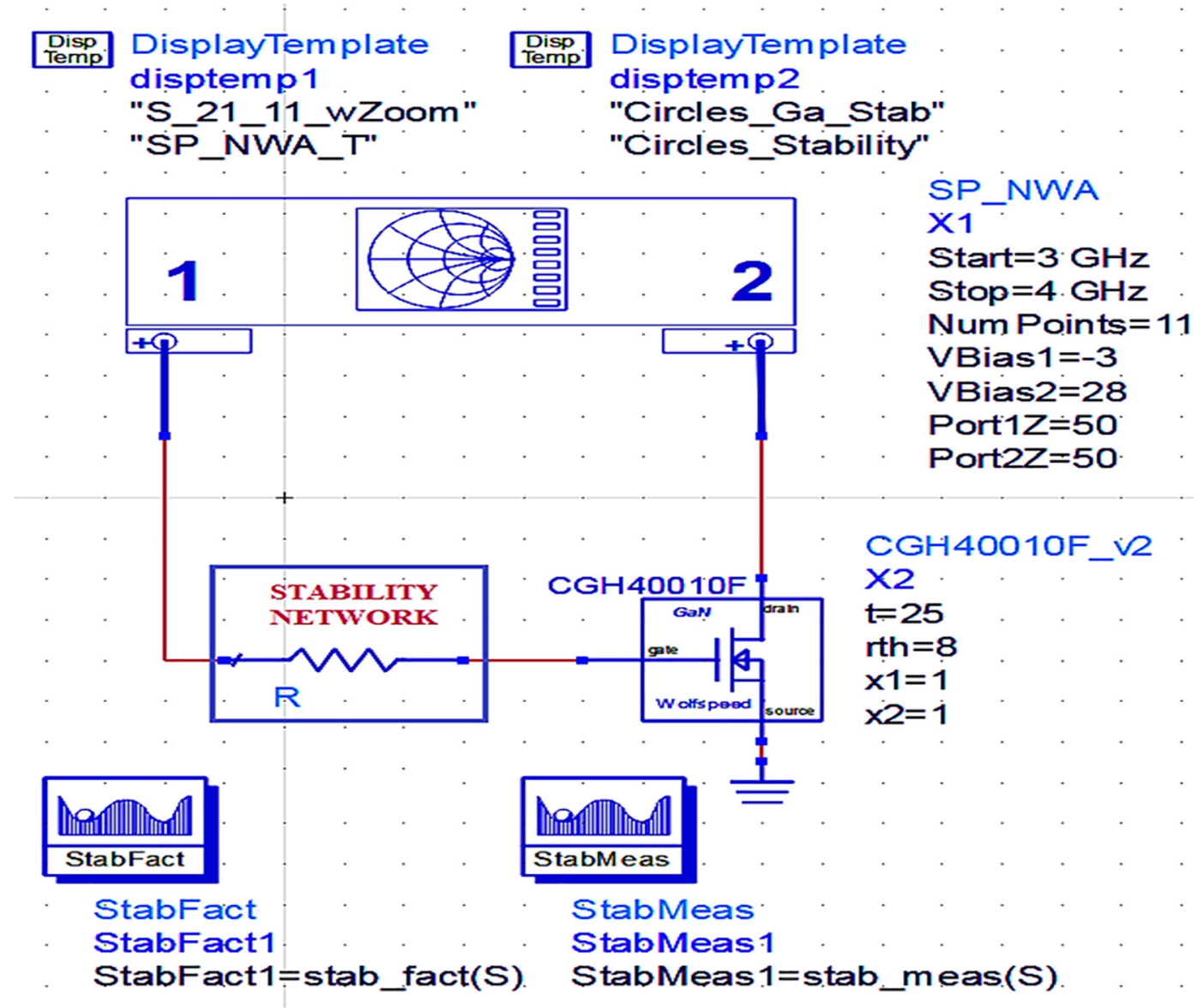

Figure 4. Stability analysis of a GaN transistor using Network Analyzer. 
Selection of optimum input and output impedances of the transistor

Generally, the transistor's optimum input and output impedances used for a PA design can be obtained by conducting load-pull simulations with the reference source and load impedances chosen from its datasheet.

As we are designing a Class-J PA in this research work, the reference source impedance can be chosen from the transistor's datasheet (if not mentioned in the datasheet, we can take approximately $(5+j * 0 \Omega)$ for any GaN device). The reference fundamental and second harmonic impedances can be calculated theoretically using Equations (1), (2) and (3).

The reference target optimum impedances required to obtain Class-J operation can be determined using the Class-J ADS workspace utility, which is developed with mathematical design equations based on the load line.

After choosing the bias (Q) point by adjusting the load line on DC-IV characteristics, which are obtained from the fixedbias network shown in Figure 3(b), and by keeping the Alpha ( $\alpha$ ) factor in Equations (1) and (2) as "zero (0)" on the slider, as shown in Figure 5, the fundamental is terminated to a resistive load and higher-order harmonics are terminated as short, which leads to the Class-B mode of operation.

The reference target optimum impedances required for Class-J operation can be obtained by moving the alpha factor $(\alpha)$ in Equations (1) and (2) from 0 to 1 on the slider in Figure 6. With this target fundamental and second harmonic load impedance, the drain voltage $\left(\mathrm{V}_{\mathrm{DS}}\right)$ is boosted with a phase shift.

Load-pull analysis

To verify the target fundamental and second harmonic load impedances shown in Figure 6, which are obtained based on the load line, load-pull simulations on the stabilized transistor must be conducted by taking them as reference impedances using a one-tone load-pull instrument at constantly available source power in the ADS EDA tool, as shown in Figure 7.

\section{Validation of optimum impedances obtained from load pull}

After obtaining the optimum source, fundamental and second harmonic load impedances from the LOADPULL simulations, corresponding to the MAX PAE, they can be validated by presenting them directly to the transistor $\left(Z_{S}\right.$ and $Z_{\mathrm{L}}$ ) instead of $50 \Omega$ termination at the source and load terminals, as shown in Figure 8 .

\section{Input and output matching network design}

After validation of the optimum input and output impedances $\left(Z_{S}\right.$ and $\left.Z_{L}\right)$, the next important step in the design is the realization of the input and output $M$. Ns to match them with the $50 \Omega$ termination source and load terminals. As we use the ADS EDA tool for this research work, impedance matching networks can be designed using three methods: Smith chart utility, impedance match utility, and equation-based lumped element $\mathrm{L}$ and $\pi$-type matching networks.

\section{CLASS J INTERACTIVE PA DESIGN UTILITY}

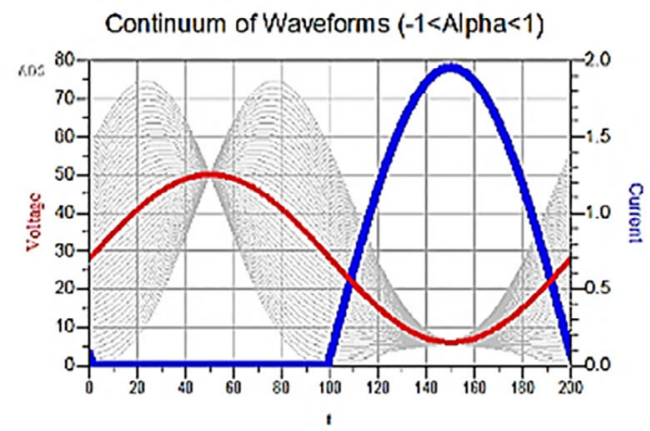

\begin{tabular}{|c|c|c|c|c|}
\hline POULINAX & lac & Ccnduction_Anglo & n」 & Duty_Cyclo \\
\hline $\begin{array}{r}40.31 \\
(\mathrm{dBm})\end{array}$ & 0.02 & 180.00 & $\begin{array}{l}\quad 61.00 \\
\text { (efficiency) }\end{array}$ & 50.00 \\
\hline
\end{tabular}

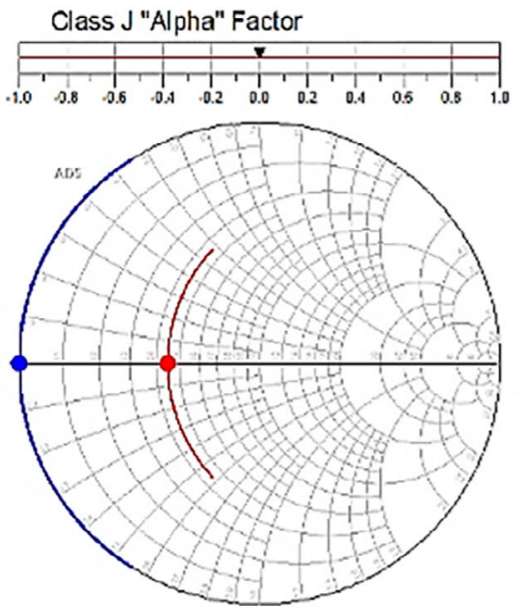

TARGET Z BASED ON LOADLINE (Red=Fundamental, Blue=2fo all other hamonics are shorts)

Figure 5. Class-B operation mode with $(\alpha=0)$. 

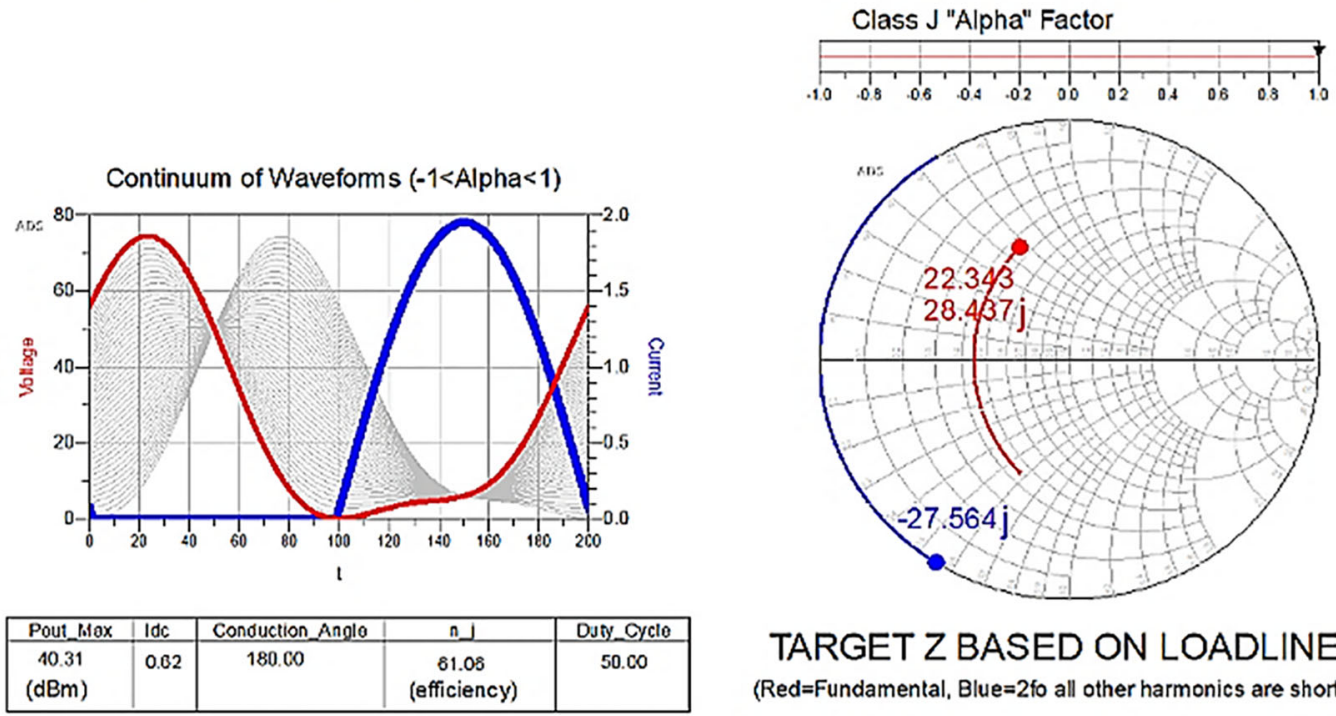

TARGET Z BASED ON LOADLINE

(Red=Fundamental, Blue $=2$ fo all other harmonics are shorts)

Figure 6. Class-J operation mode with $(\alpha=1)$.

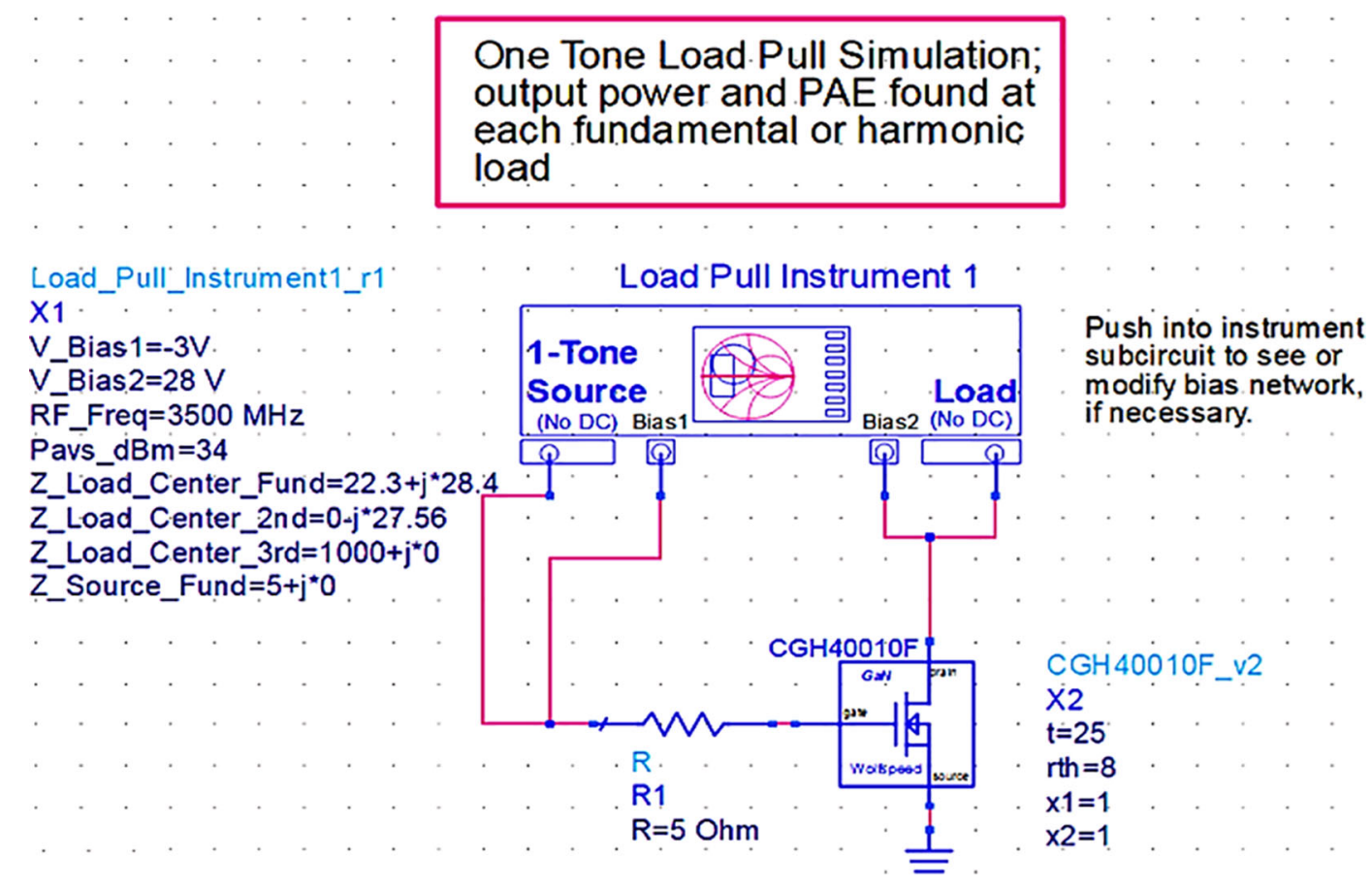

Figure 7. Load-pull analysis of the stabilized transistor.

Initially, to design the input matching network, the Smith chart component (DA_smithchart1) is terminated with a source impedance of $50 \Omega$ and the output impedance as the source impedance of the CGH40010F GaN transistor obtained from load-pull analysis. As the M. N needs to be designed at an operating frequency of $3.5 \mathrm{GHz}$, an S-parameter sweep is set up for the range of 3-4 GHz, as shown in Figure 9(a).

After setting up the S-parameter sweep, the source impedance is set as $50 \Omega$. The load impedance is set as the input impedance of the CGH40010F GaN transistor (i.e., obtained from the load-pull simulations) on the Smith chart utility, and the travel path from source impedance to the load impedance leads to an L-type input M. N, as shown in Figure 9(b). 


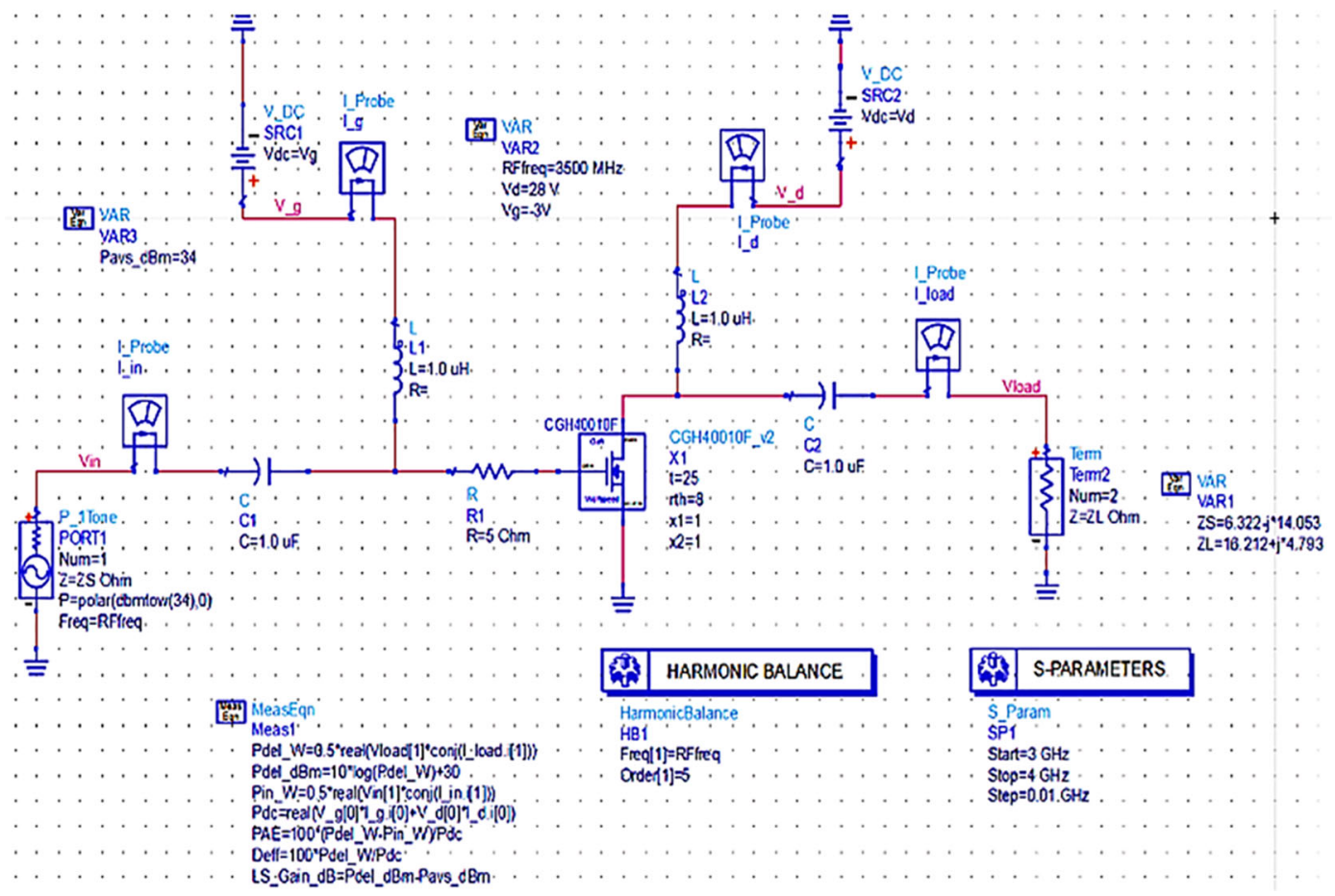

Figure 8. Validation of optimum impedances obtained from load-pull simulations.

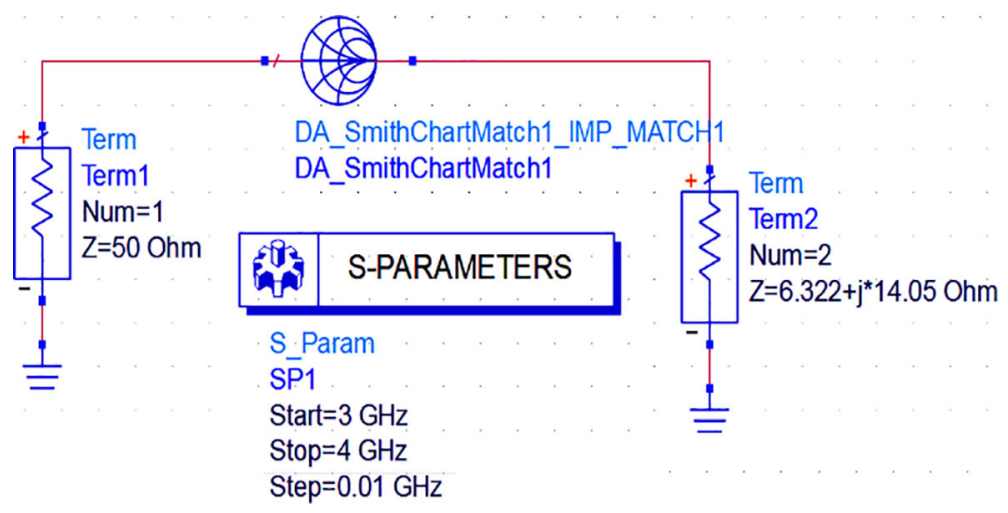

Figure 9(a). Input matching S-parameter sweep.

The output M. N is designed in the same manner as the input M.N. Nevertheless, the Smith chart component (DA _smithchart1) is terminated with source impedance as the output impedance of the CGH40010F GaN transistor (i.e., obtained from the load-pull analysis). The load is $50 \Omega$, and the S-parameter sweep is set up as an input matching network for the range of 3-4 GHz, as shown in Figure 10(a).

After setting up the operating frequency, source, and load impedances on the Smith chart utility, the travel path from source impedance to load impedance leads to an L-type output matching network, as shown in Figure 10(b).

Initially, these matching networks are designed for a bandwidth of approximately $1 \mathrm{GHz}$ with an operating frequency of 3.5 GHz (i.e., sub6 GHz). With the desired bandwidth and center frequency, the quality factor can be calculated as $\mathrm{Q}=$ f/BW. In Smith chart utility, this Q factor can be represented as Q circles. For this work, the M. Ns at input and output are designed with a Q-circle of 3.

Next, the matching networks to match the same input and output impedances (based on load-pull analysis) are represented using the Z2P_Eqn file with the $50 \Omega$ source, and load terminations are designed using the L.C. bandpass match smart component using an impedance matching utility, as shown in Figure 11(a). 

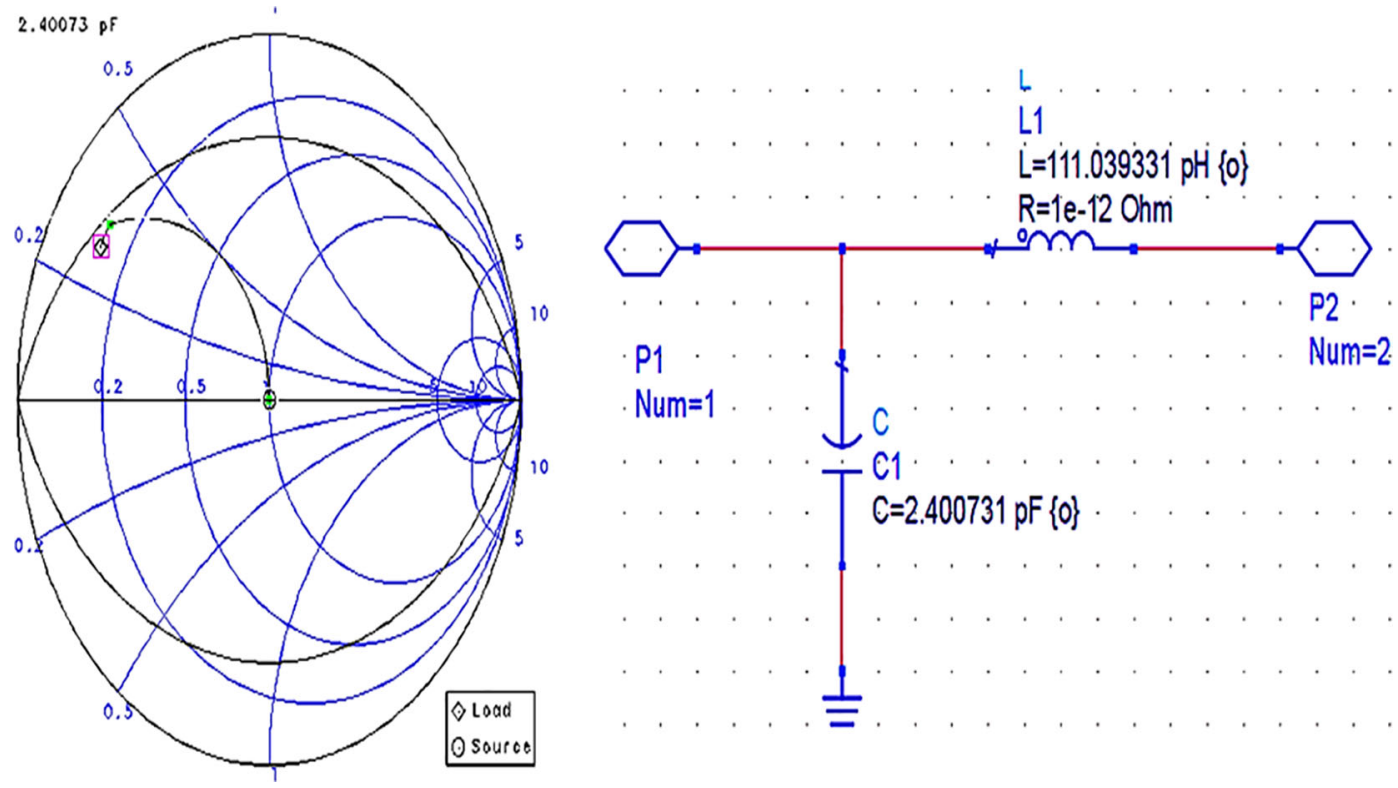

Figure 9(b). Input impedance matching network.

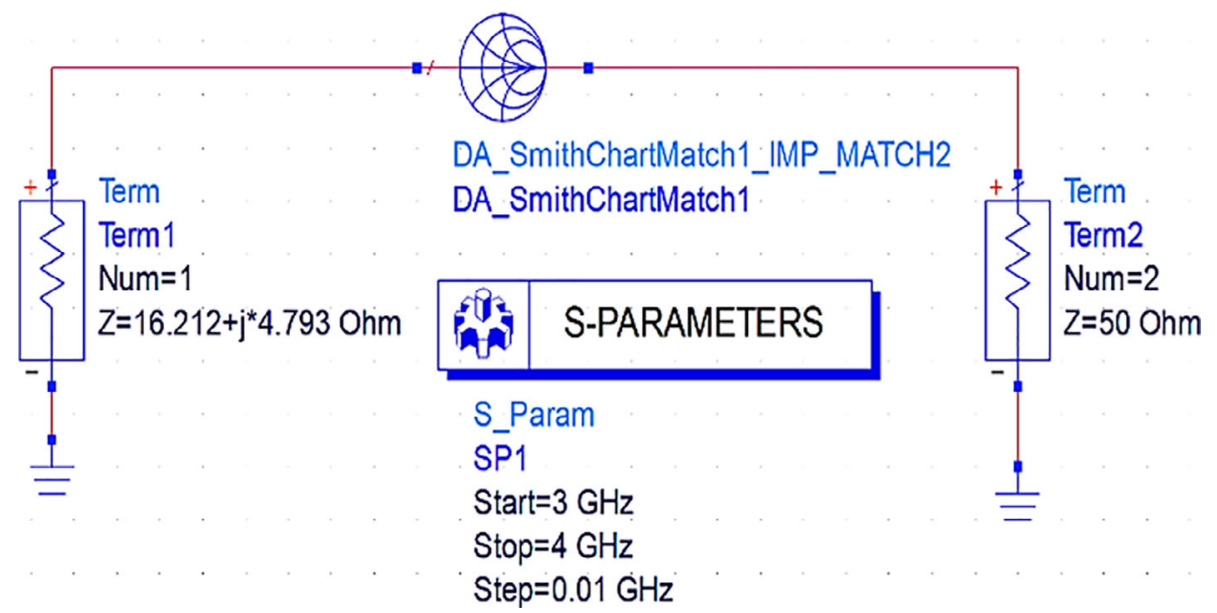

Figure 10(a). Input matching S-parameter sweep.
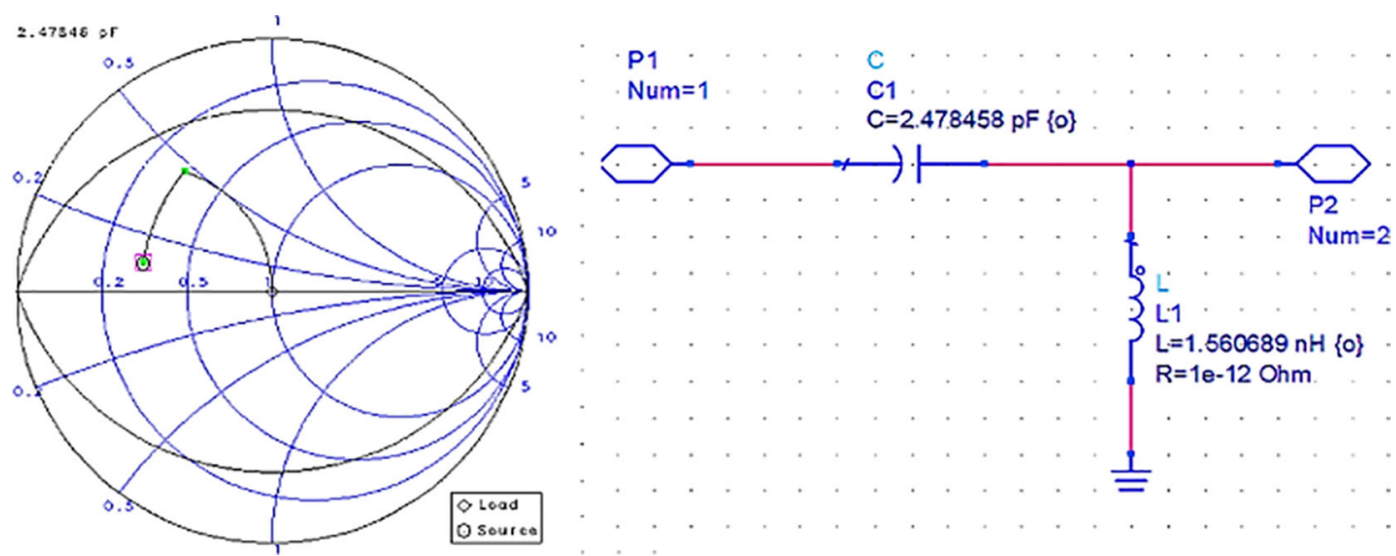

Figure 10(b). Output impedance matching network. 


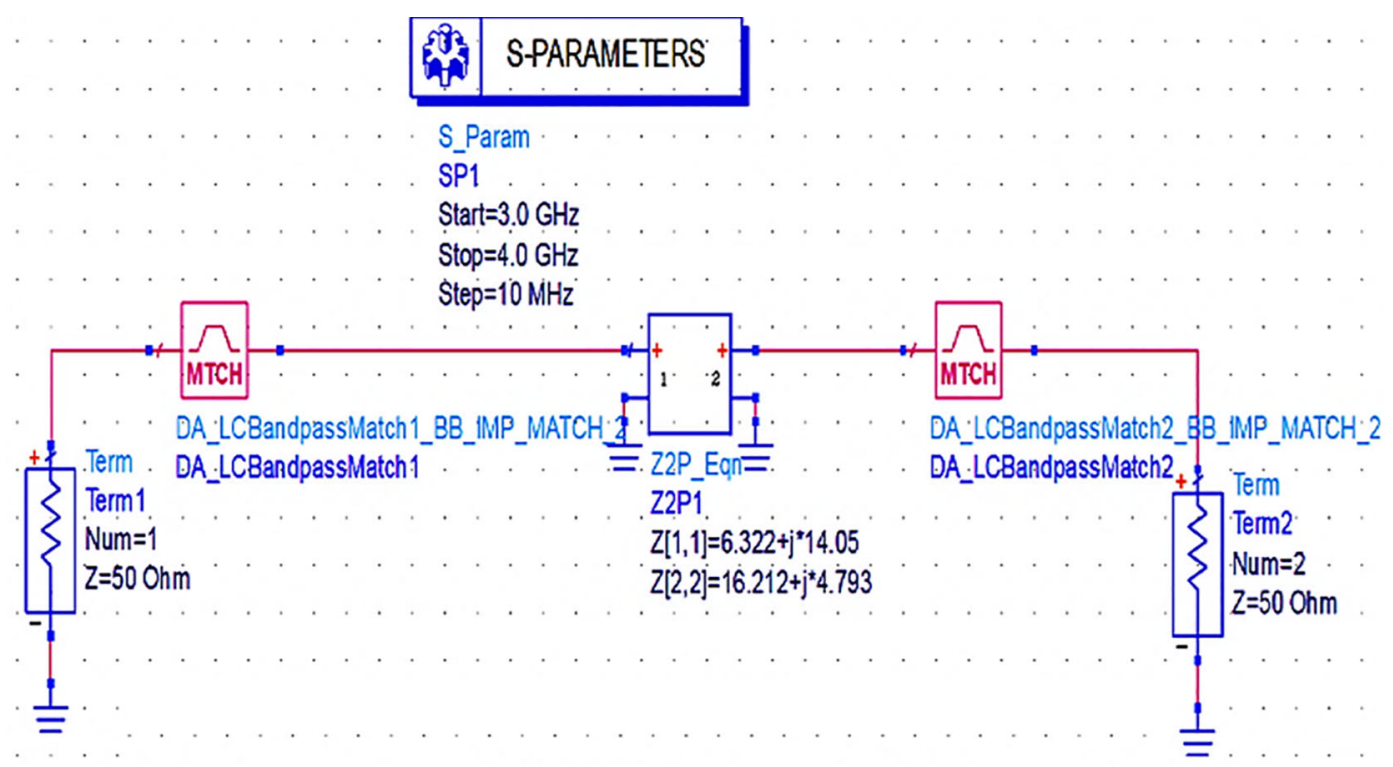

Figure 11(a). L.C. bandpass-based input and output impedance matching S-parameter sweep setup.

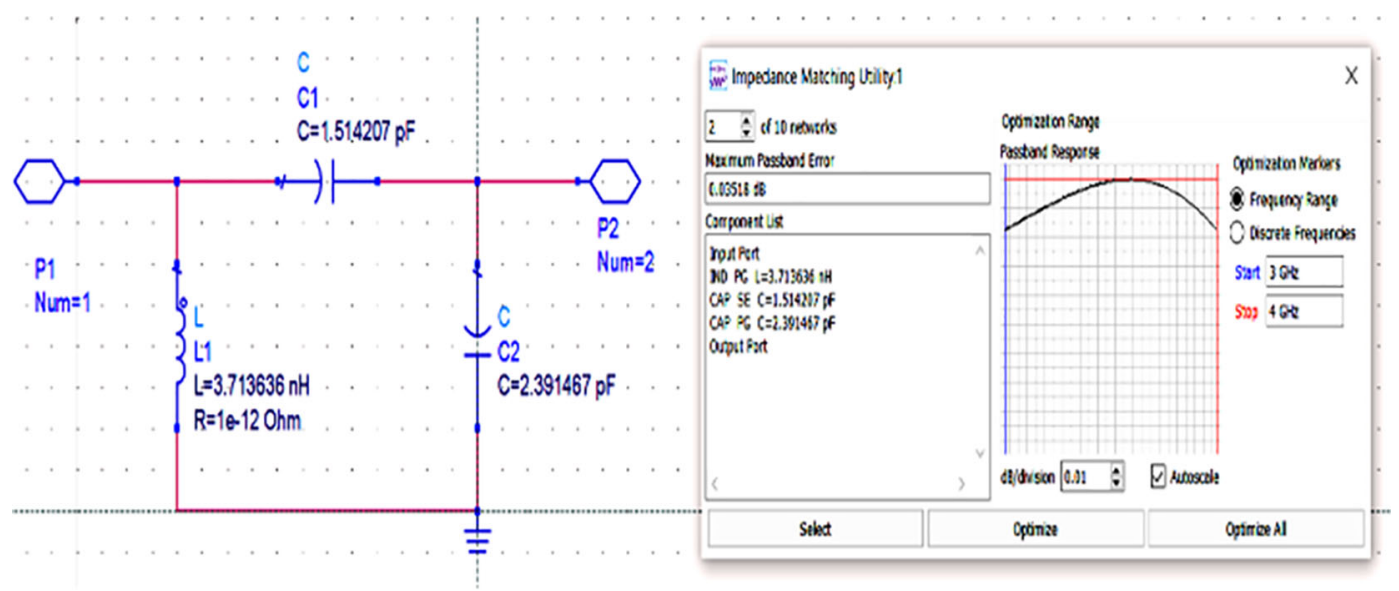

Figure 11(b). L.C. bandpass based input matching network.

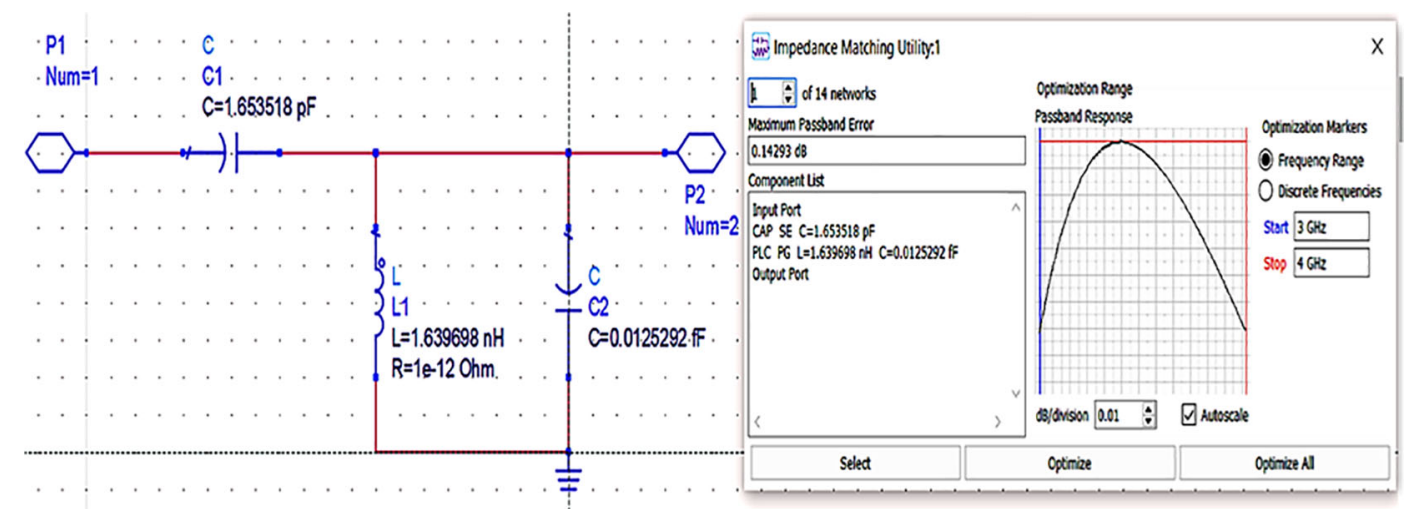

Figure 11(c). L.C. bandpass based output matching network. 
After setting up the range of frequencies (i.e., 3-4 GHz), the source and load impedances of approximately 10-14 matching network topologies are designed for input and output matching in impedance matching utility, from which the network topologies with fewer passband errors after optimization are chosen, as shown in Figures 11(b) and 11(c).

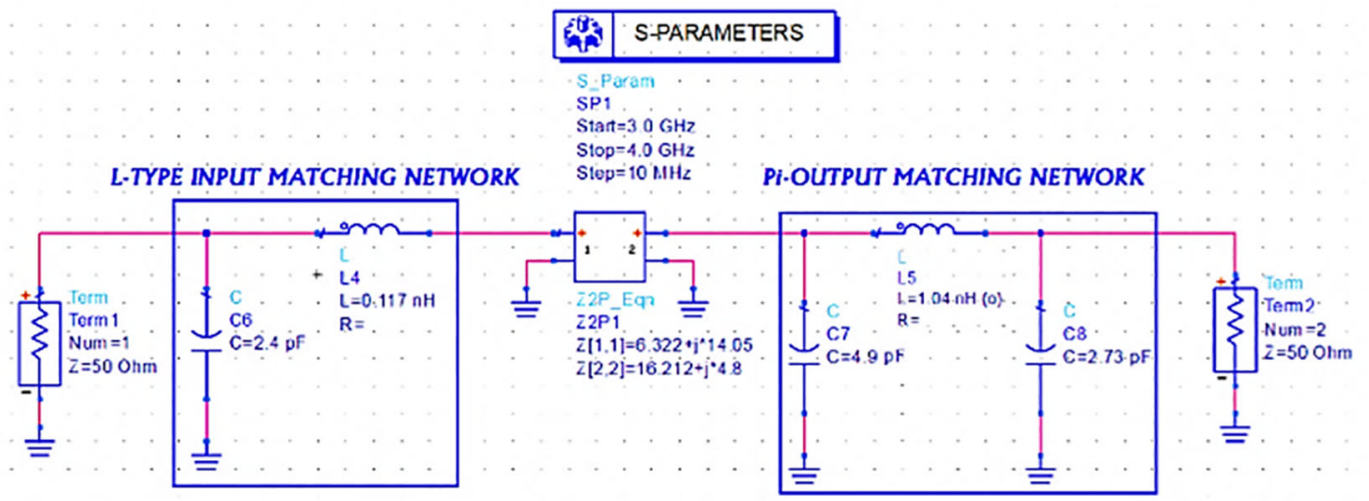

Figure 12. L-type input and $\pi$-type output matching networks S-parameter sweep setup.

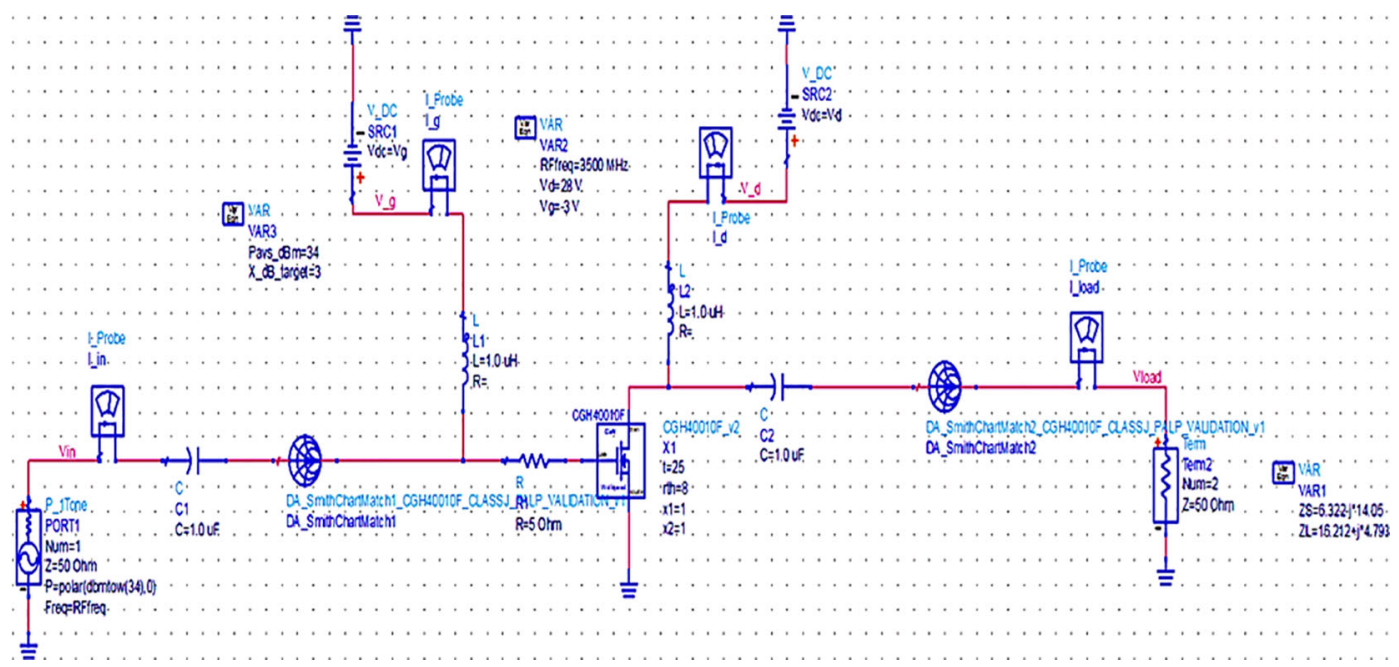

Figure 13. Schematic circuit of the Class-J PA with Smith chart utility-based matching networks.

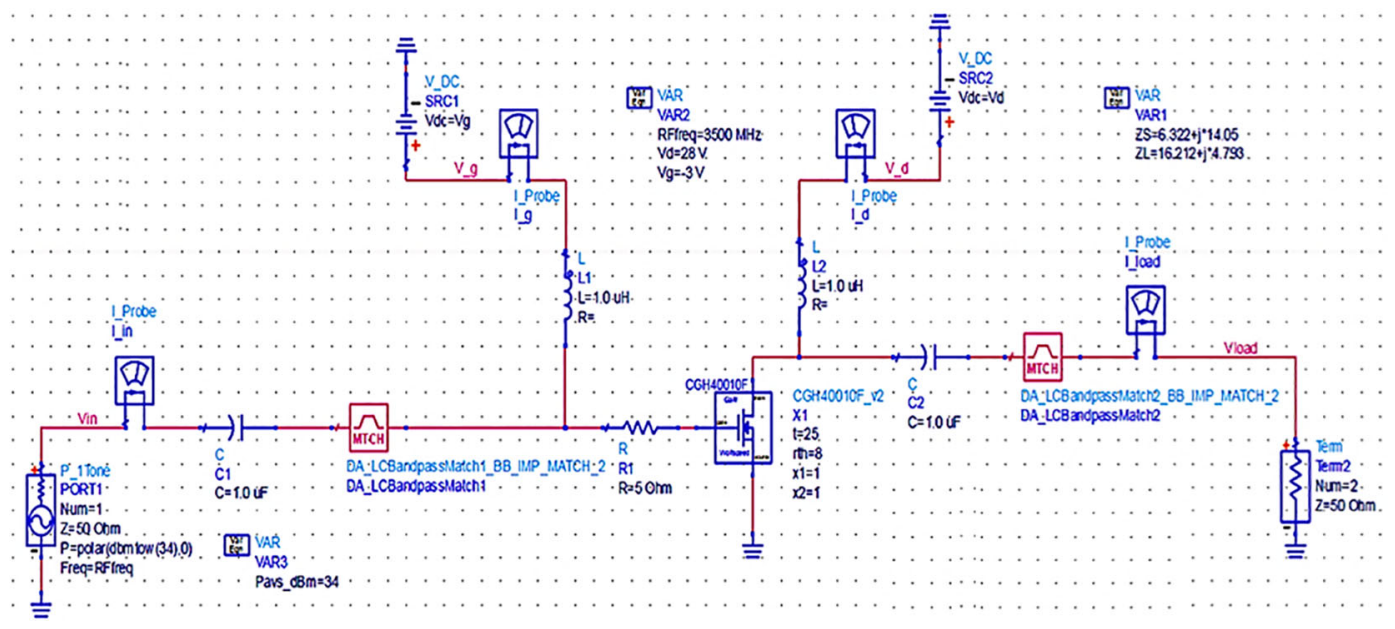

Figure 14. Schematic circuit of the Class-J PA with optimized LC-Bandpass matching networks. 


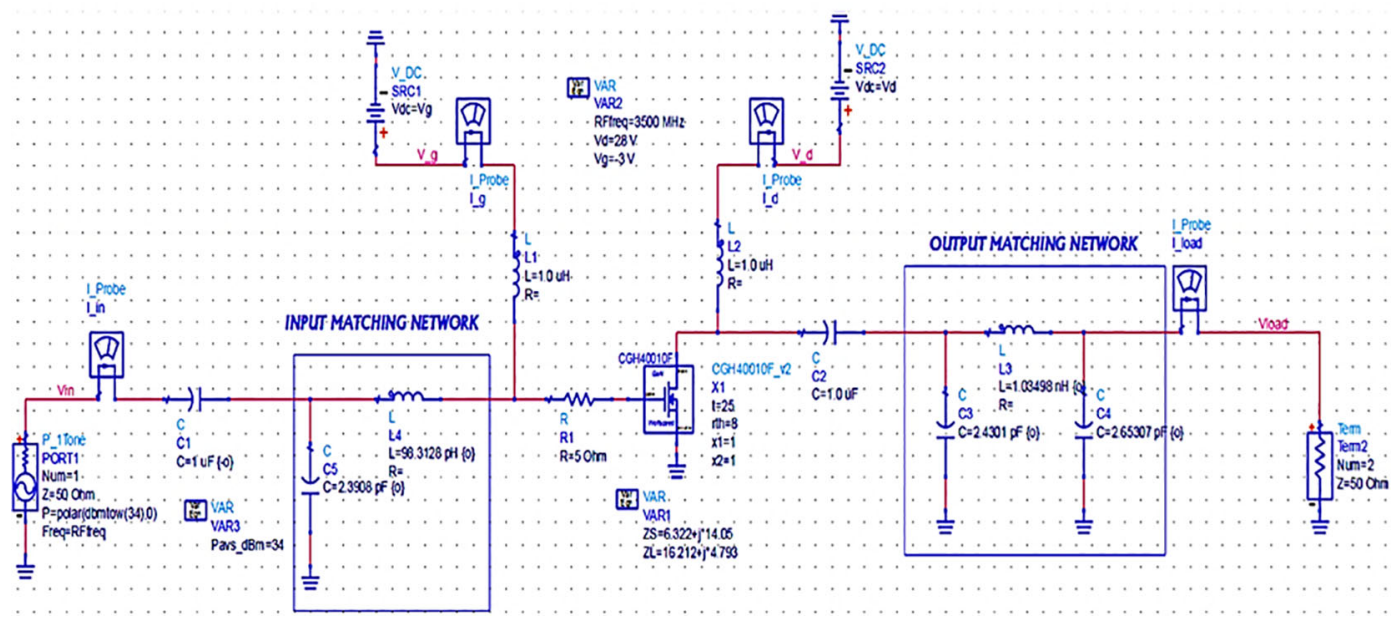

Figure 15. Schematic circuit of the Class-J PA with L- and $\pi$-type matching networks.

Later, lumped element L-type input and $\pi$-type output M. Ns to match the same input and output impedances (obtained from load-pull simulations) with the $50 \Omega$ source and load terminations are designed using basic L-type and $\pi$-type impedance matching network design equations with an operating frequency of $3.5 \mathrm{GHz}$ and a $\mathrm{Q}$-factor of 3 by setting up an S-parameter sweep for the range of 3-4 GHz, as shown in Figure 12.

Once the matching networks are designed, all topologies are placed at the input and output of the stabilized transistor to match the optimum $Z_{S}$ and $Z_{L}$ with the $50 \Omega$ termination at the source and load terminals to complete the PA design, as shown in Figures 13, 14 and 15, respectively.

The output parasitic capacitance $\mathrm{C}_{\mathrm{DS}}$ of the transistor at higher-order harmonics is considered a short circuit. Once the $\mathrm{OMN}$ is designed, the capacitive reactance to the load-line resistance ratio $\left[\mathrm{X}_{\mathrm{CDS}} / \mathrm{R}_{\mathrm{L}}\right]$ needs to be calculated. Suppose this ratio is $(<=) 1$; then, the matching network design is considered ideal. However, this ratio can also be above unity based on the technology and frequency of the device used in the design.

\section{Results}

The Class-J PA is designed using a CGH40010F transistor with GaN technology in the Advanced Design System (ADS) EDA tool. Initially, after obtaining the bias (Q) point from the D.C., the stability analysis is performed on the CGH40010F GaN transistor with an S.P. network analyzer circuit, as shown in Figure 4. The unconditional stability of the device over the desired range of frequencies can be confirmed by checking the result on the stability factor and measuring the analysis represented using Figure 16 and Table 1. It is observed that the stability factor is $>1$, and the stability measure is $>0$, which ensures that the GaN device is unconditionally stable over the desired frequency range, i.e., (3-4) GHz.

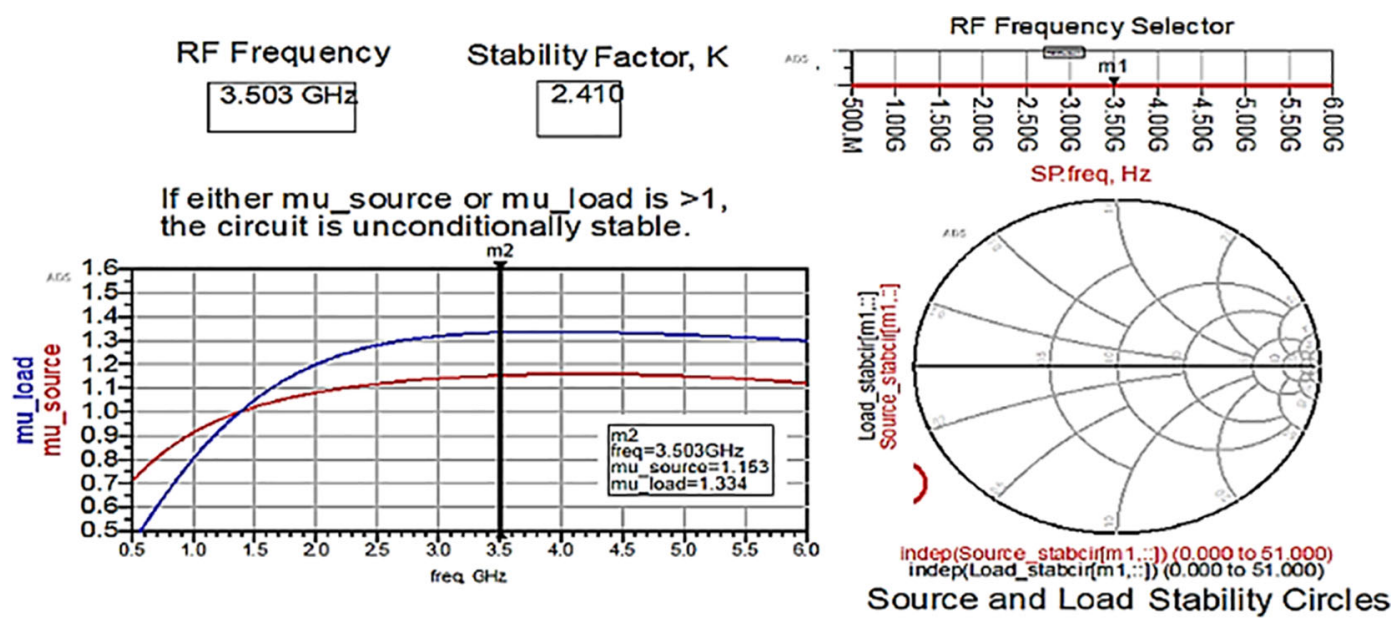

Figure 16. Stability factor analysis. 
Table 1. Stability analysis of the stabilized GaN transistor for the (3-4) GHz frequency range.

\begin{tabular}{|l|l|l|}
\hline Freq & Stab Fact 1 & Stab Meas 1 \\
\hline $3.000 \mathrm{GHz}$ & 2.111 & 1.207 \\
\hline $3.100 \mathrm{GHz}$ & 2.174 & 1.196 \\
\hline $3.200 \mathrm{GHz}$ & 2.234 & 1.185 \\
\hline $3.300 \mathrm{GHz}$ & 2.294 & 1.174 \\
\hline $3.400 \mathrm{GHz}$ & 2.352 & 1.164 \\
\hline $3.500 \mathrm{GHz}$ & 2.408 & 1.154 \\
\hline $3.600 \mathrm{GHz}$ & 2.463 & 1.145 \\
\hline $3.700 \mathrm{GHz}$ & 2.515 & 1.135 \\
\hline $3.800 \mathrm{GHz}$ & 2.565 & 1.127 \\
\hline $3.900 \mathrm{GHz}$ & 2.613 & 1.118 \\
\hline $4.000 \mathrm{GHz}$ & 2.659 & 1.111 \\
\hline
\end{tabular}

After checking the device's stability, the optimum impedances required for the Class-J PA can be obtained by conducting load d pull simulations, as shown in Figure 7, with reference to the target source and load impedances that are obtained from load-line analysis, as explained in step 4 of the Methodology section. The optimum source/input impedance obtained from the load-pull analysis is $6.315+\mathrm{j} * 13.787$, and the load/output impedance obtained is $16.151-\mathrm{j} * 0.970$, corresponding to the maximum power delivered (Pdel_dBm_MAX), as shown in Figure 17.

Similarly, the optimum source/input impedance obtained is $6.322+\mathrm{j} * 14.053$, and the load/output impedance obtained is $16.212+\mathrm{j} * 4.793$, corresponding to the maximum PAE of $66 \%$, as shown in Figure 18.

From the results of load-pull analysis, the optimum input and output impedances corresponding to the maximum PAE are chosen for the Class-J PA design and tabulated by comparison with the target source and load impedances obtained from load-line analysis-based mathematical design equations, as shown in Table 2.

Before validating the optimum source and load impedances, the PA is terminated to a $50 \Omega$ source and load terminals and the corresponding performance parameters, as shown in Figure 19.

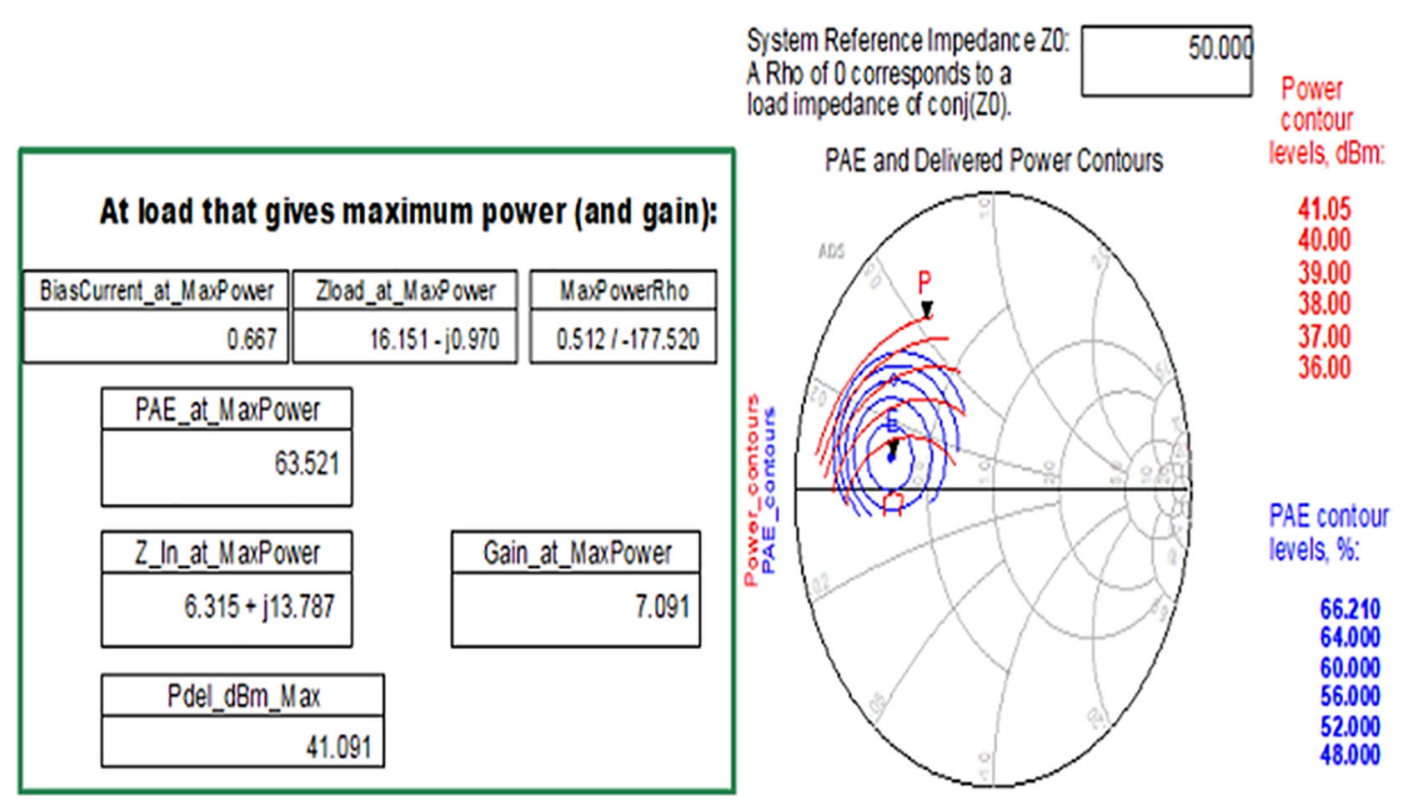

Figure 17. Optimum input and output impedances to obtain the maximum power delivered. 


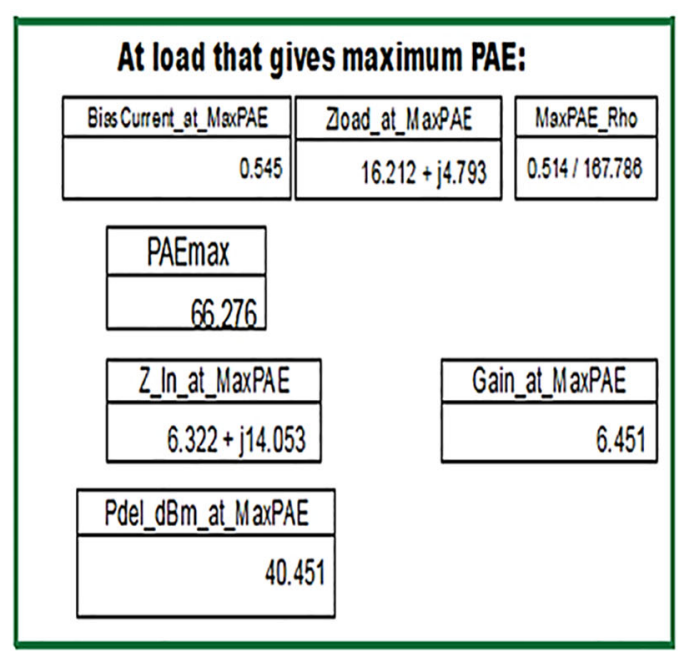

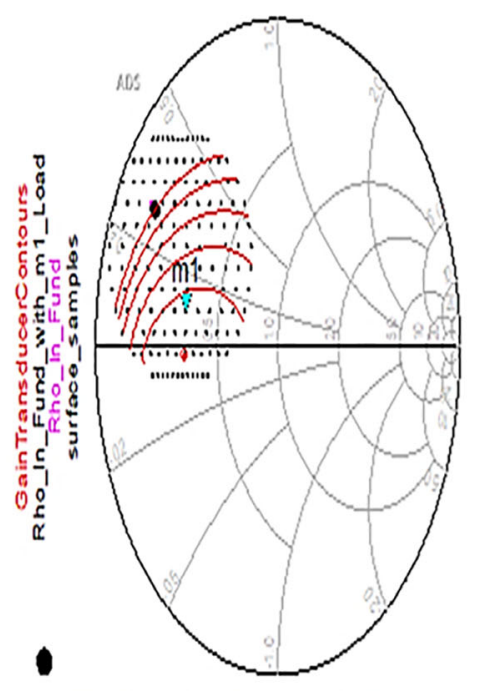

Black dot is input reflection coefficient with load selected by marker $\mathrm{m} 1$.
Available Source

Power, obm

34.000

Source Impedance

at Fundamental

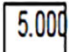

Transducer

Power Gain contour levels, $\mathrm{dB}$ :

7.084
6.000
5.000
4.000
3.000
2000

7.084

5.000

3.000

2.000

Figure 18. Optimum input and output impedances to obtain the maximum PAE.

Table 2. Comparison of input and output impedances obtained from load pull for the corresponding max PAE with load-line-based theoretical values.

\begin{tabular}{|l|l|l|l|l|}
\hline Impedance & PAE_Max (\%) & Pout $(\mathbf{d B m})$ & Load-pull & Theory/load line \\
\hline Source/input & 66.276 & 40.451 & $6.3+\mathrm{j} * 14.1 \Omega$ & $5+\mathrm{j} * 0 \Omega$ \\
\hline Load/output & 66.276 & 40.451 & $16.2+\mathrm{j} * 4.8 \Omega$ & $22.3+\mathrm{j} * 28.4 \Omega$ \\
\hline
\end{tabular}

\begin{tabular}{|r|c|c|r|r|}
\hline Pdel_dBm & PAE & \multicolumn{1}{c|}{ Deff } & LS_Gain_dB & \multicolumn{1}{c|}{ Pdel_W } \\
\hline 38.924 & 35.861 & 41.438 & 4.924 & 7.800 \\
& & & & \\
\hline
\end{tabular}
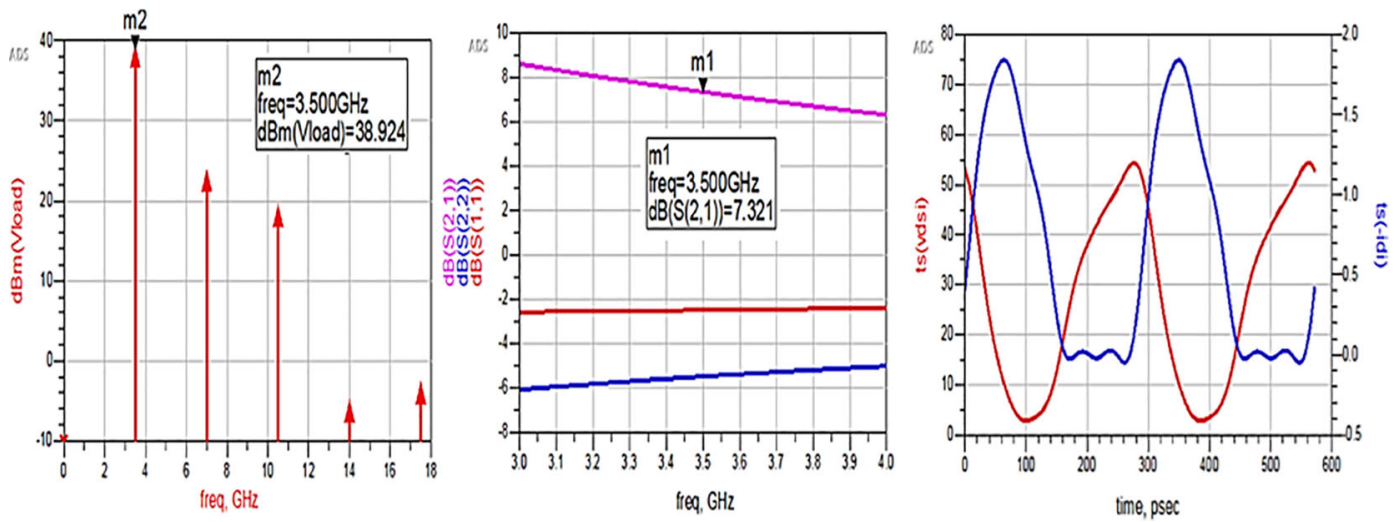

Figure 19. Performance parameters corresponding to a $\mathbf{5 0} \Omega$ source and load terminations.

Figure 19 shows that the performance parameters such as power delivered, large-signal and small-signal gains, D. E, and PAE are very low, as the CGH40010F GaN transistor does not terminate to optimum impedance values.

By terminating the transistor with the optimum impedance values obtained using load-pull simulations corresponding to the maximum PAE, harmonic balance S-parameter simulations are validated by running, as shown in Figure 8, and the respective performance parameters are shown in Figure 20. 


\begin{tabular}{|r|c|r|r|r|}
\hline Pdel_Bm & PAE & Deff & LS_Gain_dB & Pdel_W \\
\hline 41.532 & 60.445 & 73.352 & 7.532 & 14.230 \\
& & & & \\
\hline
\end{tabular}
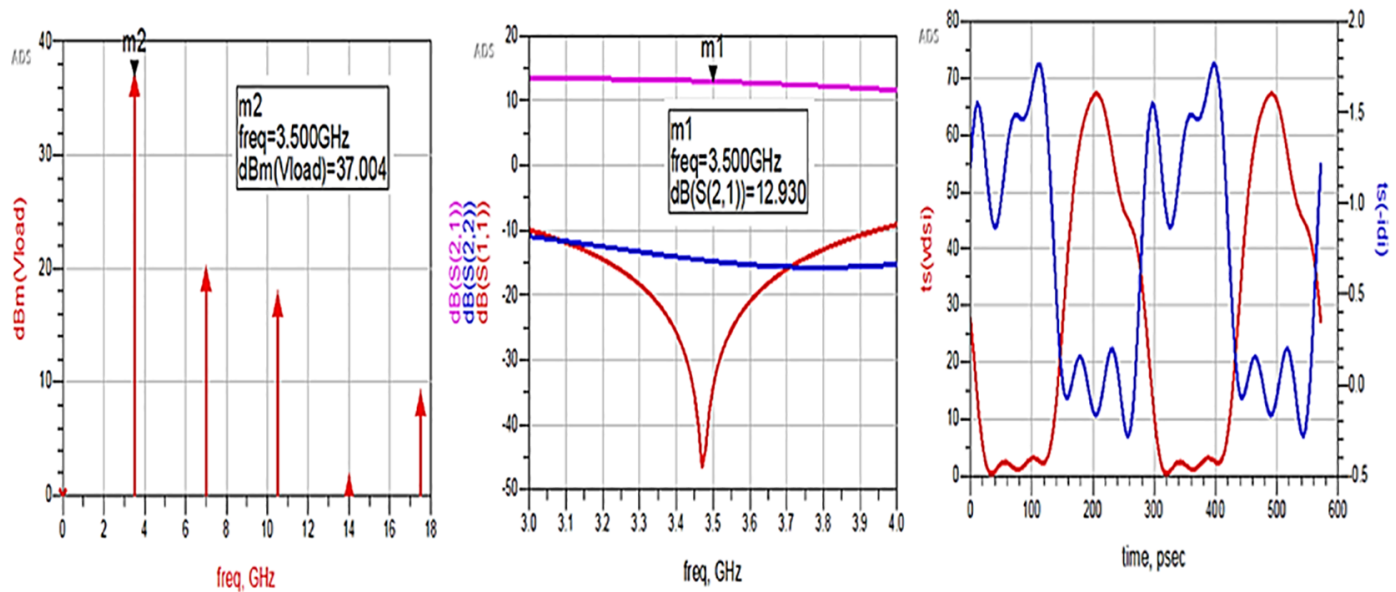

Figure 20. Performance parameters corresponding to the optimum source and load terminations without matching networks.

From Figure 20, the performance parameters such as power delivered, large-signal and small-signal gains, drain efficiency and PAE are improved and nearly equal to the values obtained from load-pull simulations, as the input and output impedances of the $\mathrm{CGH} 40010 \mathrm{~F}$ GaN transistor are terminated to optimum impedance values. In addition, the reflection coefficients $\mathrm{S}(1,1)$ and $\mathrm{S}(2,2)$ are not as expected.

After validation of optimum impedances obtained from load-pull analysis, the M. Ns are designed as explained in step 7 of the Methodology section and placed at the respective input and output terminals of the PA, as Smith chart components are shown in Figure 13. Finally, these matching network elements are optimized and updated using an optimization tool in ADS, as shown in Figure 21.

After optimizing the performance parameters such as power delivered and large-signal and small-signal gains, PAE and D. E are shown in Figure 22. The reflection coefficients $S(1,1)$ and $S(2,2)$ are obtained as expected with the optimization of input and output matching networks.

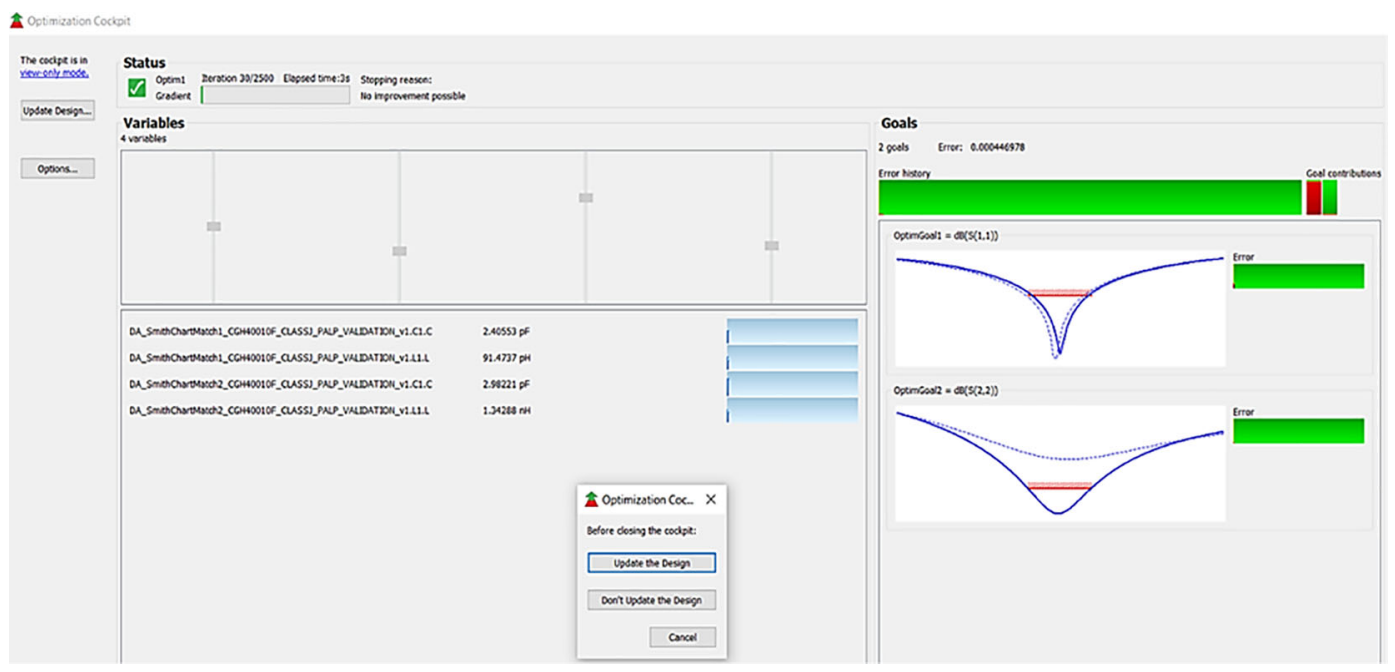

Figure 21. Optimization of input and output matching network elements. 


\begin{tabular}{|r|c|c|r|r|}
\hline Pde__oBm & PAE & \multicolumn{1}{c|}{ Deff } & LS_Gan_oB & \multicolumn{1}{c|}{ Póel_W } \\
\hline 40.789 & 57.300 & 72.397 & 6.789 & 11.991 \\
\hline
\end{tabular}
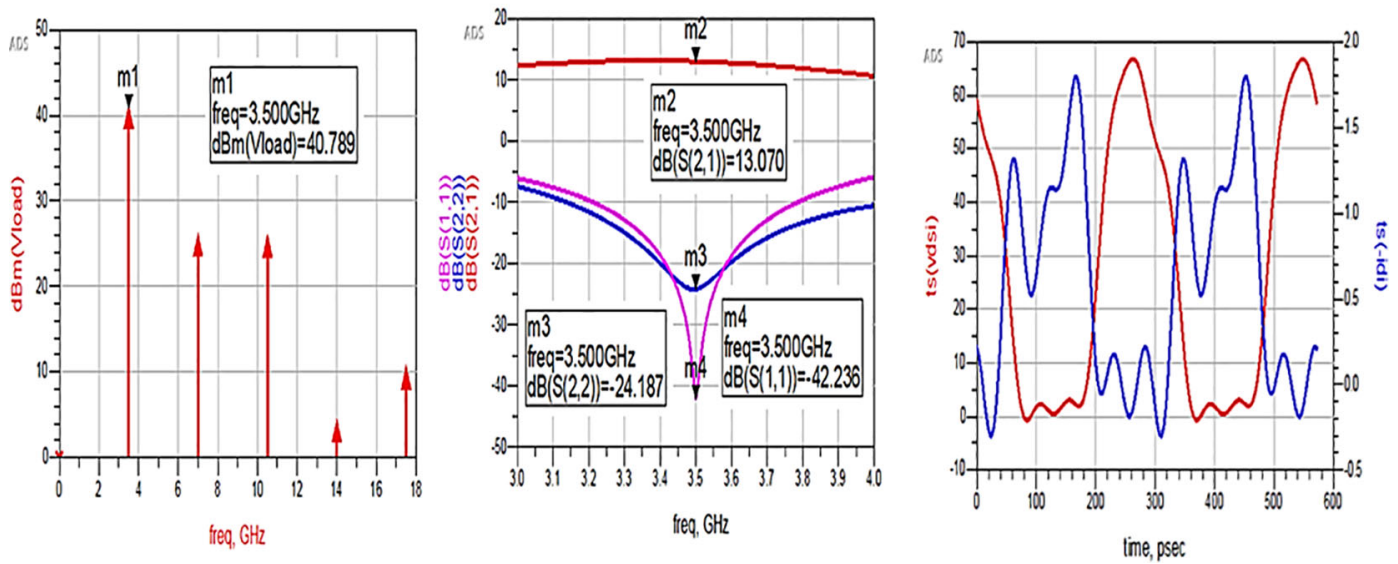

Figure 22. Performance parameters corresponding to the optimum source and load terminations using Smith chart utility-based matching networks.

The matching networks that are designed using L.C. bandpass match with the impedance matching utility, as explained in step 7 of the Methodology section, are placed at respective input and output terminals of the PA, as shown in Figure 14. Then, these matching network elements are optimized and updated using an optimization tool in ADS, as shown in Figure 23.

After optimizing the performance parameters such as power delivered and large-signal and small-signal gains, PAE and D. E are shown in Figure 24. The performance parameters are improved slightly with the optimization of the matching networks that are designed using the impedance matching utility.

The matching networks that are designed using basic L-type input and $\pi$-type output matching design equations, as explained in step 7 of the Methodology section, are placed at the input and output terminals of the PA, as shown in Figure 15, and then these matching network elements are optimized and updated using an optimization tool in ADS, as shown in Figure 25.

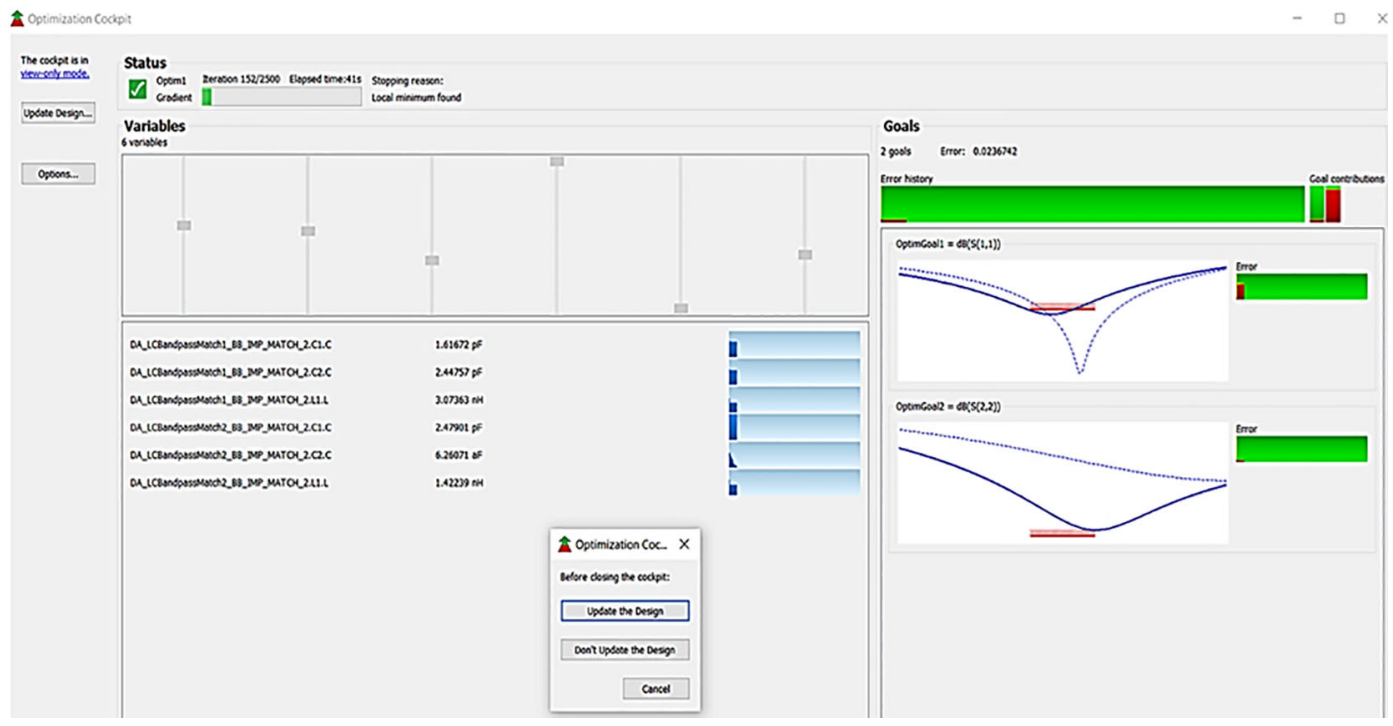

Figure 23. Optimization of input and output matching network elements. 


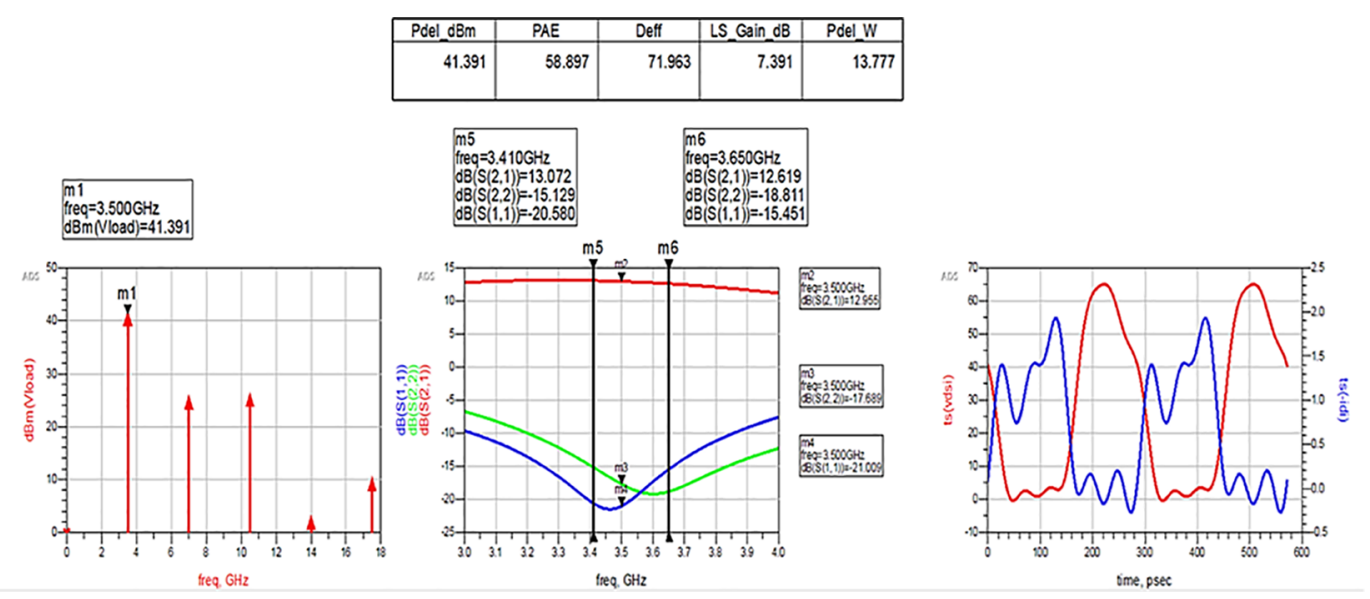

Figure 24. Performance parameters corresponding to the optimum source and load terminations using LC bandpass matching networks.

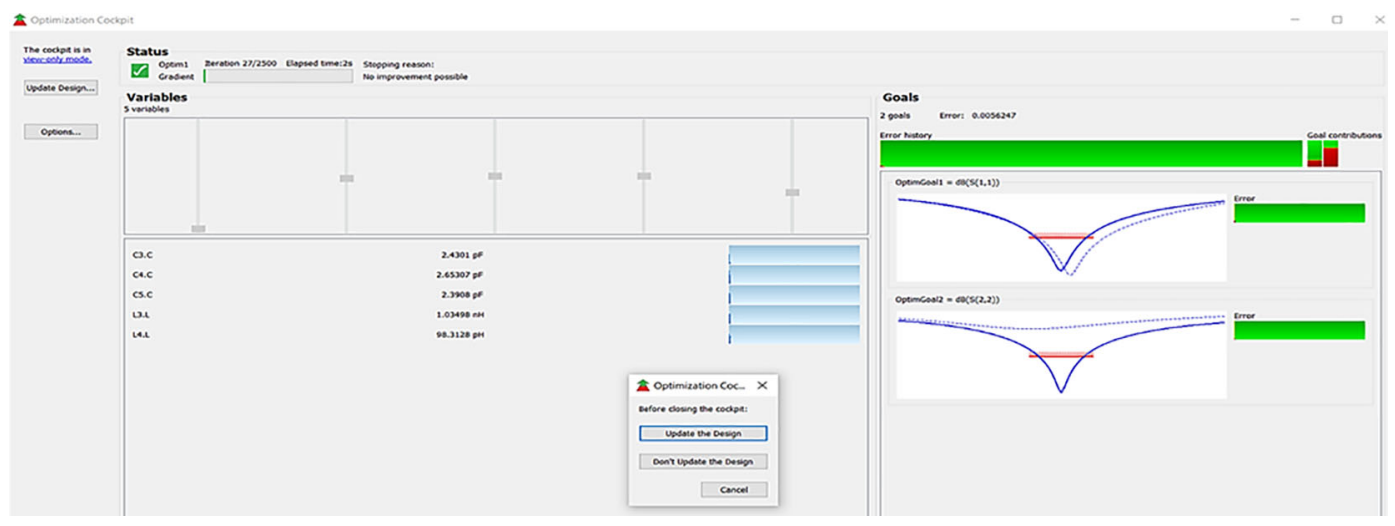

Figure 25. Optimization of input and output matching network elements.

After optimizing the performance parameters such as power delivered and large-signal and small-signal gains, PAE and D. E are shown in Figure 26. The performance parameters are obtained as expected with the optimization of input and output matching networks.

All the numerical values of performance parameters such as power delivered (Pdel_W, Pdel_dBm_MAX) in watts and dBm, large-signal gain (LS_Gain_dB), PAE and D. E (Deff) that are shown in Figures 19, 20, 22, 24, and 26, corresponding to without and with three matching topologies, are computed with many equations using the "MeasEqn" of the harmonic balance HB simulator. The load voltage is plotted as the spectrum in $\mathrm{dBm}$, and intrinsic voltages/currents are plotted as time-domain signals using an (HB) simulation controller in ADS. The desired half-rectified intrinsic drain voltage and currents with small overlap that represent the Class-J mode of operation were obtained, and reflection coefficients $\mathrm{S}(1,1)$ and $\mathrm{S}(2,2)>-10 \mathrm{~dB}$ over a frequency range from (3.3-3.7) GHz were observed from Figure 26. The comparison of the performance parameters of the Class-J PA with and without matching networks obtained for different source and load terminations is shown in Table 3.

The above comparison table shows that among the 3 methods used for matching networks, the Class-J PA with L-type input and $\pi$-type output matching networks exhibits expected performance parameters that are obtained from load-pull simulations (i.e., 66\% of PAE and $40 \mathrm{dBm}$ of max power output), as shown in Figure 18.

To validate the variation in the performance parameters with respect to the input power sweep, HB simulations were performed on the proposed Class-J PA by taking the available source power (Pavs_dBm) as the sweeping parameter. Figure 27 shows the simulation results of important performance parameters such as drain efficiency, PAE, large-signal gain, and power delivered corresponding to the available source power (Pavs_dBm) sweep. These results demonstrate 


\begin{tabular}{|r|c|c|r|r|}
\hline Pdel_dBm & PAE & Deff & LS_Gain__B & Pdel_W \\
\hline 41.400 & 67.284 & 82.118 & 7.400 & 13.803 \\
\hline
\end{tabular}
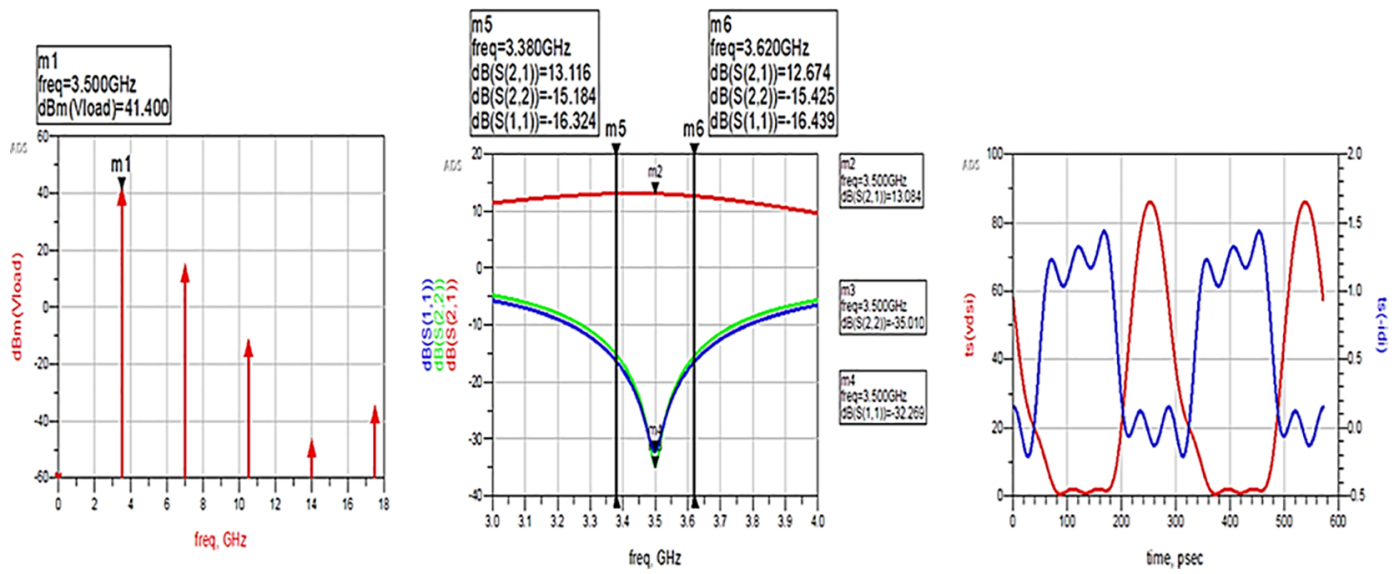

Figure 26. Performance parameters corresponding to the optimum source and load terminations using L-type input and $\pi$-type output matching networks.

Table 3. Performance comparison of the proposed Class-J PA with and without matching networks (M.Ns).

\begin{tabular}{|c|c|c|c|c|c|}
\hline $\begin{array}{l}\text { Mode of } \\
\text { source \& Load } \\
\text { termination }\end{array}$ & $\begin{array}{l}50 \Omega \\
\text { without } \\
\text { M.N }\end{array}$ & $\begin{array}{l}\text { Optimum ZS } \\
\text { and ZL } \\
\text { without M.N }\end{array}$ & $\begin{array}{l}50 \Omega \text { with Smith } \\
\text { chart utility- } \\
\text { based M.N }\end{array}$ & $\begin{array}{l}50 \Omega \text { with } \\
\text { impedance match } \\
\text { utility-based M.N }\end{array}$ & $\begin{array}{l}50 \Omega \text { with L-type } \\
\text { I/P and } \pi \text {-type } \\
\text { O/P M.N }\end{array}$ \\
\hline Feature & Class-J & Class-J & Class-J & Class-J & Class-J \\
\hline Freq [GHz] & 3.5 & 3.5 & 3.5 & 3.5 & 3.5 \\
\hline Vsupply [V] & 28 & 28 & 28 & 28 & 28 \\
\hline LS_Gain [dB] & 5 & 7 & 7 & 7.4 & 7.4 \\
\hline SS_Gain [dB] & 7 & 12.9 & 13 & 12.95 & 13.1 \\
\hline Pout [dBm] & 39 & 41.5 & 41 & 41.4 & 41.4 \\
\hline $\max$ PAE [\%] & 36 & 60 & 57 & 59 & 67 \\
\hline $\max D E[\%]$ & 41 & 73 & 72 & 72 & 82 \\
\hline BW [GHz] & $3-4$ & $3-4$ & $3-4$ & $3-4$ & $3-4$ \\
\hline
\end{tabular}

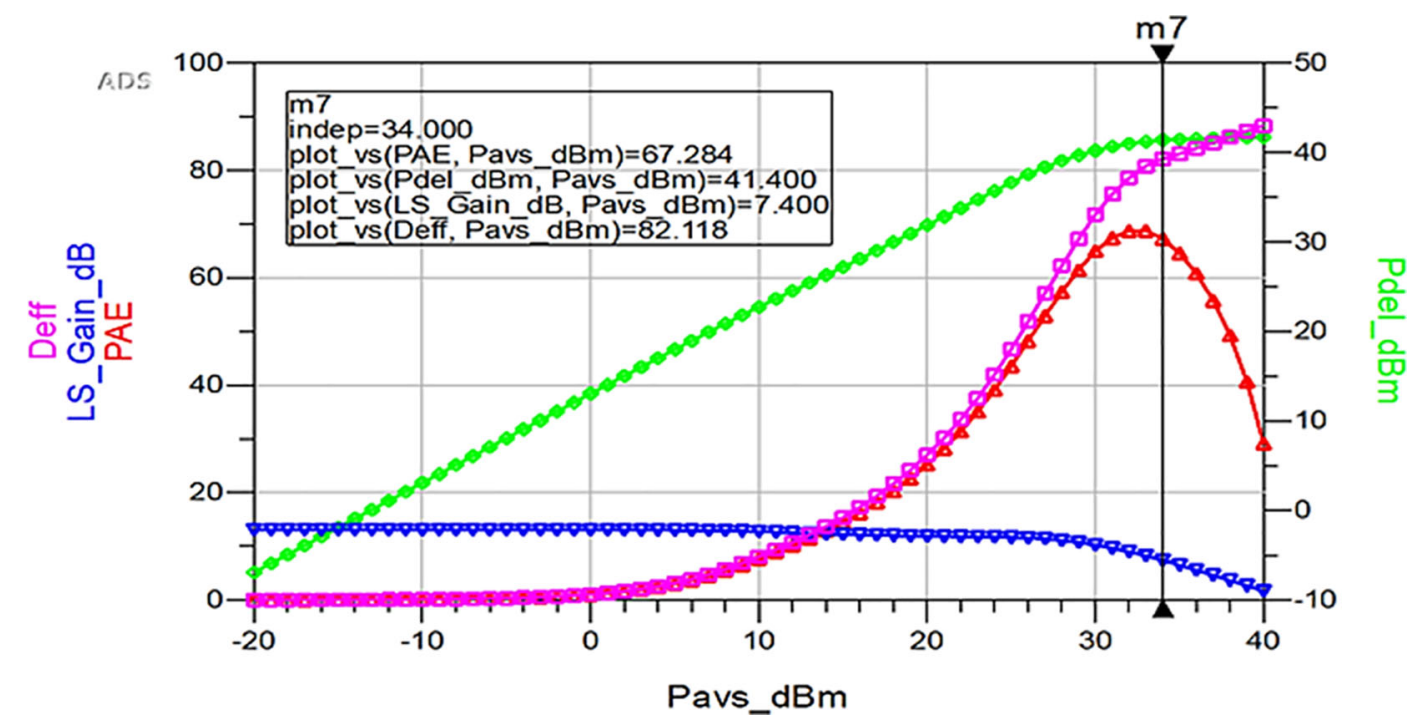

Figure 27. Performance parameters of the Class-J PA w.r.t Pavs_dBm sweep. 


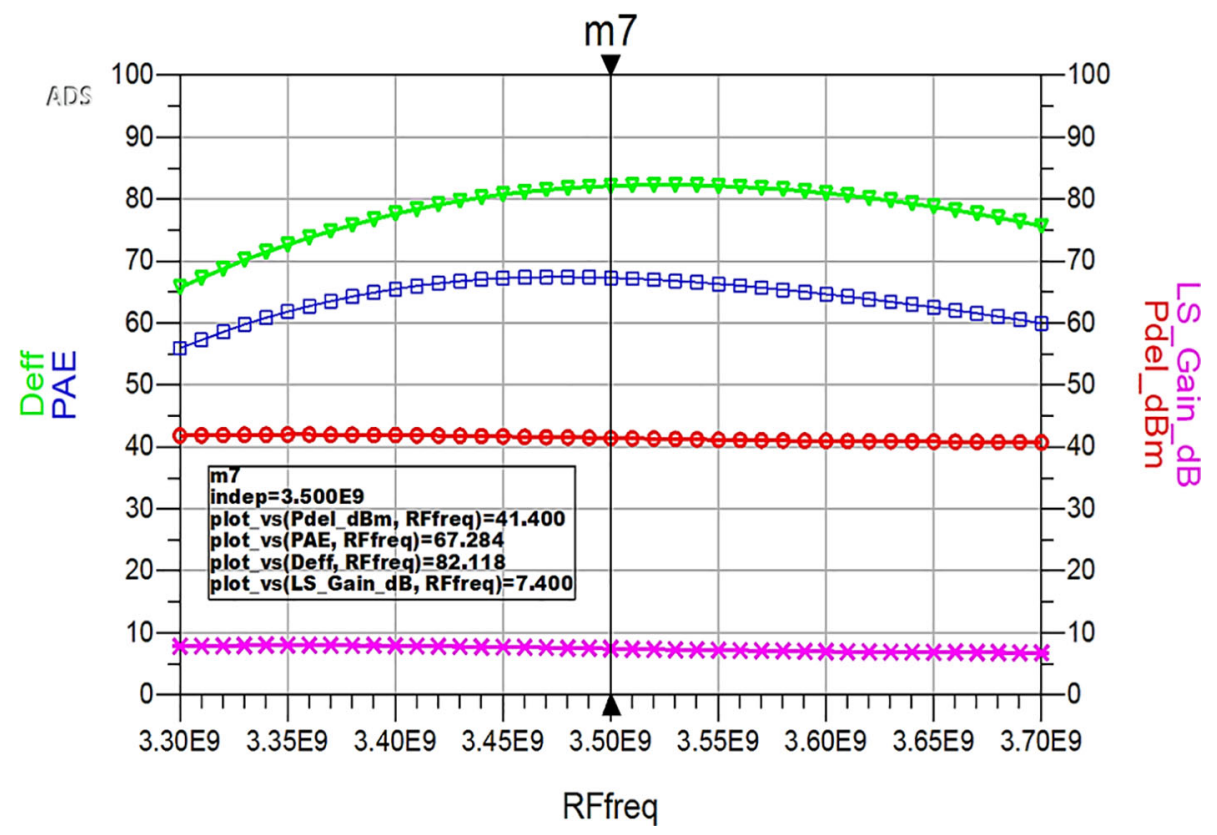

Figure 28. Performance parameters of the Class-J PA w.r.t R.F. frequency.

that, a maximum power output of $41.4 \mathrm{dBm}$ with a power gain of approximately $7.4 \mathrm{~dB}$, max D. E of $82 \%$, and max PAE of $67 \%$ for the corresponding available source power of $34 \mathrm{dBm}$ with a $28 \mathrm{~V}$ power supply into a $50 \Omega$ load.

Similarly, HB simulations were performed to validate the performance parameter variation of the proposed Class-J PA with L-type input and $\pi$-type output matching networks with respect to the input RF frequency, and the corresponding results are displayed in Figure 28. These results reveal that a power output above $40 \mathrm{dBm}$ with a power gain of approximately $7 \mathrm{~dB}$ over a bandwidth of approximately $400 \mathrm{MHz}$ (i.e., $3.3 \mathrm{GHz}$ to $3.7 \mathrm{GHz}$ ) and max PAE and D. E of $67 \%$ and $82 \%$, respectively, are obtained at a $3.5 \mathrm{GHz}$ center frequency.

\section{Discussion}

Finally, the improved performance parameters of the proposed Class-J PA with L-type input and $\pi$-type output matching networks are compared with similar Class-J PAs in the literature. ${ }^{30-34}$ As these PAs were designed at different frequencies and technologies, it is difficult to compare their performances. However, it can be noted that the Class-J PA design is proposed with a compact transmission line-based output matching network $(\mathrm{OMN})$ in $^{30}$ that uses the same transistor technology $(\mathrm{GaN})$ of this work to obtain broadband and highly efficient amplification and achieves a maximum drain efficiency of $75 \%$. Although our proposed PA is designed at different frequencies, its bandwidth is the same as that of this PA, and its transmission line-based M. Ns use a large chip area compared to the M. Ns of our work. A microwave Class-J PA for Wi-Fi IEEE802.11a Bluetooth applications designed with a methodology similar to that of this work in the same ADS EDA tool is presented in, ${ }^{31}$ which uses a GaAs transistor as an active device but achieves a power output of $21 \mathrm{dBm}$ and D. E of $69 \%$. A fully integrated Class-J PA designed at $5 \mathrm{GHz}$ for WLAN 802.11ax applications was presented in $^{32}$ that uses $\mathrm{GaN}$ on $\mathrm{SiC}$ technology with the same $\mathrm{V} \mathrm{dd}=28 \mathrm{~V}$ to provide a maximum PAE of $55 \%$ and output power of $38 \mathrm{dBm}$, and it was mentioned that the performance of this PA can be enhanced further by employing DPD. However, the gain of this PA is high compared to our work, as it is designed as a multistage PA. A Class-J PA designed for X-Band is presented in. ${ }^{33}$ It uses the active load modulation technique, facilitates the PA's integrated implementation by eliminating the doubler and filter networks of conventional Class-J2 PAs, and achieves a drain efficiency of $71 \%$ and a PAE of 50\%. However, the broad B.W. is not achieved because of harmonic tuners, and the auxiliary network used for phase shifting may need additional circuitry and space. A Class-J PA design with a novel direct M. N synthesis technique for broadband operation is presented in. ${ }^{34}$ The PAE and output power $(\mathrm{dBm})$ are almost the same at the frequency $(3.5 \mathrm{GHz})$ of our proposed work. Although the synthesis technique is novel, the transmission line-based MNs may occupy a large chip area. In addition, an integrated Class-J PA using CMOS technology is presented in, ${ }^{22}$ in which the effect of knee voltage is considered for deriving modified design equations. However, the staked FET must be used for implementation because of the CMOS PA's low breakdown voltage, whereas our work uses a GAN device with a high breakdown voltage. The performance comparison discussed thus far is summarized in Table 4. The PAE and DE of this work are better than those of other works shown in Table 4. 
Table 4. Performance Comparison of Class-J PAs.

\begin{tabular}{|l|l|l|l|l|l|}
\hline REF & This work & $\mathbf{3 0}$ & $\mathbf{3 1}$ & $\mathbf{3 2}$ & $\mathbf{3 3}$ \\
\hline Technology & GaN & GaN & GaAs & GaN & GaAs \\
\hline Feature & Class-J & Class-J & Class-J & Class-J & Class-J \\
\hline Freq. $[\mathrm{GHz}]$ & 3.5 & 2 & 2.4 & 5 & 10 \\
\hline Pout $[\mathrm{dBm}]$ & 41.4 & 42 & 21 & 37.7 & 29 \\
\hline max PAE [\%] & 67 & 66 & - & 54.6 & 50 \\
\hline max DE [\%] & 82 & 75 & 69 & - & 71 \\
\hline BW [GHz] & $3.3-3.7$ & $1.8-2.2$ & - & $4.9-5.9$ & $9.1-10.8$ \\
\hline
\end{tabular}

\section{Conclusions}

A 3.5 GHz Class-J PA design with lumped element-based input and output matching networks that are suitable for 5G smart meter/grid applications is presented in this paper. The proposed Class-J PA design methodology is demonstrated in a stepwise manner. It is observed that with a small overlap between the intrinsic half-wave rectified current and voltage waveforms at the drain, this Class-J mode PA can be as linear as Class-B or AB modes because of its non-switching mode of operation. From the simulation results, we conclude that the proposed Class-J PA obtains a maximum drain efficiency of $82 \%$, which is better than similar Class-J PAs reported in the literature. A PAE of $67 \%$ with a $13 \mathrm{~dB}$ small-signal gain at $3.5 \mathrm{GHz}$ and an output power of $40 \mathrm{dBm}(41.4 \mathrm{dBm}$ peak) with a power gain of approximately $7 \mathrm{~dB}$ over a bandwidth of approximately $400 \mathrm{MHz}$ (i.e., $3.3 \mathrm{GHz}$ to $3.7 \mathrm{GHz}$ ) are achieved with no harmonic traps, unlike in Class-B mode PAs, which makes this Class-J PA superior to other PA modes and more appealing for emerging wireless communication networks used for AMI of smart meters in 5G smart grids. However, the PAE and BW of the proposed Class-J PA can still be improved by fine-tuning the designed matching networks. This work is in progress to achieve desired specifications of $5 \mathrm{G}$ smart grid applications.

\section{Data availability}

No data are associated with this article.

\section{Author contributions}

Mr. Nagisetty Sridhar-original drafting of manuscript preparation, Dr Chinnaiyan Senthilpari-validation and Supervision, Dr. Mardeni R-cosupervision. All the authors agreed to the final version of this manuscript.

\section{Acknowledgments}

We would like to express our sincere thanks to the Multimedia University and Ministry of Higher Education (MOHE), Malaysia, for funding this research work through FRGS MMUE/190075.

\section{References}

1. Dahiya M: Need and Advantages of $\mathbf{5 G}$ wireless Communication Systems. Int. J. Adv. Res. Com. Sci. \& Manag. Studies. 2017; 5: 48-51.

2.

Reference Source

3.

Reference Source

4. Niknejad M, Thyagarajan S, Alon E, et al.: A circuit designer's guide to $5 \mathrm{G} \mathrm{mm}$-wave. 2015 IEEE Custom Integrated Circuits Conference (CICC). 2015; pp. 1-8, Publisher Full Text

5. Agiwal M, Roy A, Saxena N: Next Generation 5G Wireless Networks: A Comprehensive Survey. IEEE Communications Surveys \& Tutorials. 2016; vol. 18(no. 3): pp. 1617-1655. Publisher Full Textthird quarter.

6. Lie DYC, Mayeda JC, Li Y, et al.: A Review of 5G Power Amplifier Design at $\mathbf{c m}$-Wave and $\mathbf{m m}$-Wave Frequencies. Wirel. Commun. Mob. Comput. 2018; vol. 2018: 1-16 pages. Article ID 6793814. Publisher Full Text
7. Reynaert P, Steyaert M: RF Power Amplifiers for Mobile Communications. 2006 Publisher Full Text

8. Murad SAZ, Ahamd MF, Shahimin MM, et al.: High efficiency CMOS Class E power amplifier using $\mathbf{0 . 1 3} \boldsymbol{\mu \mathrm { m }}$ technology. 2012 IEEE Symposium on Wireless Technology and Applications (ISWTA). 2012; pp. 85-88.

Publisher Full Text

9. Sahu S, Deshmukh A: Design of High Efficiency Two Stage Power Amplifier in $0.13 \mu \mathrm{M}$ RF CMOS Technology for $2.4 \mathrm{GHZ}$ WLAN Application. Int. J. VLSI Design \& Communi. Syst. 2013; 4: 31-40. Publisher Full Text

10. Yi-Hsin Chen K, Kao C-YC, Lin K: A 24 GHz CMOS power amplifier with successive IM2 feed-forward IMD3 cancellation. 2015 IEEE MTT-S International Microwave Symposium. 2015; 1-4. Publisher Full Text

11. Kunihiro K, Hori S, Kaneko T: High Efficiency Power Amplifiers for Mobile Base Stations: Recent Trends and Future Prospects 
for 5G. IEICE Trans. Fundam. Electron. Commun. Comput. Sci. 2018; Volume E101.A(Issue 2): Pages 374-384. Released February 01, 2018, Online ISSN 1745-1337, Print ISSN 0916-8508. Publisher Full Text

12. Reynaert $\mathrm{P}, \mathrm{Cao} \mathrm{Y}$, Vigilante $\mathrm{M}$, et al.: Doherty techniques for 5G RF and $\mathbf{m m}$-wave power amplifiers. 2016 International Symposium on VLSI Technology, Systems and Application (VLSI-TSA). 2016; pp. 1-2. Publisher Full Text

13. Asbeck PM: Will Doherty continue to rule for 5G?. 2016 IEEE MTT-S International Microwave Symposium (IMS). 2016; pp. 1-4. Publisher Full Text

14. Jayamon JA, Buckwalter JF, Asbeck PM: $\mathbf{2 8} \mathbf{~ G H z}>\mathbf{2 5 0} \mathbf{~ m W}$ CMOS Power Amplifier Using Multigate-Cell Design. 2015 IEEE Compound Semiconductor Integrated Circuit Symposium (CSICS). 2015; pp. 1-4. Publisher Full Text

15. Baimel D, Tapuchi S, Baimel N: Smart Grid Communication Technologies. J. Power and Energy Engine. 2016; 04: 1-8. Publisher Full Text

16. Reference Source

17. Jiang J, Qian Y: Distributed Communication Architecture for Smart Grid Applications. IEEE Commun. Mag. December 2016; vol. 54(no. 12): pp. 60-67. Publisher Full Text

18. Reka SS, Dragičević T, Siano P, et al.: Future Generation 5G Wireless Networks for Smart Grid: A Comprehensive Review. Energies. Jun. 2019; 12(11): 2140 Publisher Full Text

19. Cripps SC: RF Power Amplifiers for Wireless Communications. Boston, MA: Artech; 2nd ed. 2006

20. Wright $\mathrm{P}$, Lees J, Benedikt J, et al.: A methodology for realizing high-efficiency class-J in a linear and broadband PA. IEEE Trans. Microwave Theory Tech. Dec. 2009; 57(12)): 3196-3204. Publisher Full Text

21. Rezaei S, Belostotski L, Ghannouchi FM, et al.: Integrated Design of a Class-J Power Amplifier. IEEE Transactions on Microwave Theory and Techniques. April 2013; 61(4): 1639-1648. Publisher Full Text

22. Dong $Y$, Mao L, Xie S: Fully Integrated Class-J Power Amplifier in Standard CMOS Technology. IEEE Microwave and Wireless Components Letters. Jan. 2017; 27(1): 64-66. Publisher Full Text

23. Alizadeh A, Frounchi M, Medi A: Waveform Engineering at Gate Node of Class-J Power Amplifiers. IEEE Transactions on Microwave
Theory and Techniques. July 2017; 65(7): 2409-2417. Publisher Full Text

24. Alizadeh A, Medi A: Investigation of a Class-J Mode Power Amplifier in Presence of a Second-Harmonic Voltage at the Gate Node of the Transistor. IEEE Transactions on Microwave Theory and Techniques. Aug. 2017; 65(8): 3024-3033. Publisher Full Text

25. Alizadeh A, Yaghoobi M, Medi A: Class-J2 Power Amplifiers. IEEE Transactions on Circuits and Systems I: Regular Papers. Aug. 2017; vol. 64(no. 8): pp. 1989-2002. Publisher Full Text

26. Hiew YK, Aripin NM, Jayavalan S, Din NM: Spectrum band for smart grid implementation in Malaysia. 2013 IEEE Student Conference on Research and Development. 2013; pp. 26-30. Publisher Full Text

27.

Reference Source

28. Reference Source

29. Parvez I, Sarwat A: A Spectrum Sharing based Metering Infrastructure for Smart Grid Utilizing LTE and WiFi. Advances in Science, Technology and Engineering Systems Journal. 2019; 4: 70-77. Publisher Full Text

30. Xie D, You CJ, Yang Y, et al.: Broadband and highly efficient class-j power amplifier with compact output matching network. 2017 Sixth Asia-Pacific Conference on Antennas and Propagation (APCAP). 2017; pp. 1-3. Publisher Full Text

31. Abdulhamid M, James K, Farhan M: On the Design of ClassMicrowave Power Amplifier. The Scientific Bulletin of Electrical Engineering Faculty. 2019; 19(1): 6-12. Publisher Full Text

32. Liu B, Mao M, Boon CC, et al.: A Fully Integrated Class-J GaN MMIC Power Amplifier for 5-GHz WLAN 802.11ax Application. IEEE Microwave and Wireless Components Letters. May 2018; 28(5): 434-436. Publisher Full Text

33. Alizadeh S, Hassanzadehyamchi AM, Kiaei S: An X-Band ClassPower Amplifier with Active Load Modulation to Boost Drain Efficiency. IEEE Transactions on Circuits and Systems I: Regular Papers. May 2020; 67: 3364-3377. Publisher Full Text

34. Zeng $\mathrm{M}$, Chen $\mathrm{S}$, Wang $\mathrm{W}$, et al.: A novel direct matching network synthesis technique and its application to broadband class-J power amplifier. July 2020; 30.

Publisher Full Text 
The benefits of publishing with F1000Research:

- Your article is published within days, with no editorial bias

- You can publish traditional articles, null/negative results, case reports, data notes and more

- The peer review process is transparent and collaborative

- Your article is indexed in PubMed after passing peer review

- Dedicated customer support at every stage

For pre-submission enquiries, contact research@f1000.com 